\title{
Proteome analysis of sesame leaves in response to waterlogging stress at vegetative and flowering stages
}

\author{
H.-J. JUNG ${ }^{1}$, S.K. ROY', S.-W. CHO ${ }^{2}$, S.-J. KWON ${ }^{1}$, C. KUN ${ }^{3 *}$, H.-C. CHUN ${ }^{4}$, and S.-H. WOO ${ }^{1 *}$ \\ Department of Crop Science, Chungbuk National University, Cheong-ju, 28644 Republic of Korea ${ }^{l}$ \\ Department of Crop Science and Biotechnology, Chonbuk National University, Jeon-ju, 54896 \\ Republic of Korea ${ }^{2}$ \\ Center for Research Equipment, Korea Basic Science Institute, Ochang, Cheong-ju, 28119 Republic of Korea ${ }^{3}$ \\ National Institute of Crop Science, Rural Development Administration, Miryang, 50424 Republic of Korea ${ }^{4}$
}

\begin{abstract}
Waterlogging, a major environmental stress, impairs plant growth and development and induces synthesis of different proteins. To understand the molecular mechanisms coupled with morpho-physiological alterations underlying waterlogging tolerance, the LTQ-FTICR MS/MS technique was employed to map the proteomes of leaves of sesame grown under control and waterlogged conditions. The waterlogging treatment caused dramatic alterations in morphological and biochemical properties of the leaves of sesame. For proteome analysis, more than 75 reproducible protein spots were identified on 2-DE gels wherein 51 protein spots ( $\geq 1.5$-fold change) were used for analysis by mass spectrometry. Among 51 differentially abundant proteins, 20 were specific to the 10-leaf stage and 31 were specific to the flowering stage. Most of the differentially abundant proteins were involved in group metabolism, and energy and stress defense. Oxygen-evolving enhancer protein 1, ATP synthase subunit, heat shock proteins, glutamine synthetase, glyceraldehyde-3-phosphate dehydrogenase, and superoxide dismutase were upregulated under waterlogging. However, the photosynthesis- and protein biosynthesisrelated proteins (e.g., ribulose-1,5-bisphosphate carboxylase/oxygenase activase, and S-adenosylmethionine synthase 1) were down-regulated under waterlogging. The protein interaction network indicates that energy metabolism- and stressand defense-related proteins were involved in the protein-protein interaction network, which could form an indispensable network in sesame leaves. To this end, physiological results highlighted the impairment of photosyntheis, which is consistent with results obtained at the proteome level. The upregulation of metabolism-, energy-, and stress defenserelated proteins in response to waterlogging stress may provide new insights into the complex mechanisms underlying waterlogging tolerance in sesame.
\end{abstract}

Additional key words: LTQ-FTICR MS/MS technique, photosynthesis, protein biosynthesis, Sesamum indicum, stress defense.

\section{Introduction}

Waterlogging is one of the major environmental stresses, and it is becoming frequently increasing worldwide due to climate change (Bailey-Serres et al. 2012). The soil is considered to be waterlogged when it is completely saturated with water (at least $20 \%$ higher than the field capacity; Aggarwal et al. 2006). Waterlogging has become an important constraint on crop production globally as it causes a significant reduction in growth and photosynthesis, accelerates leaf senescence, induces oxidative stress, etc., all leading to yield loss (Yamauchi et al. 2014, Wang et al. 2016a).

Sesame (Sesamum indicum L.), an emerging oilseed crop worldwide owing to its high oil content, has the potential capacity to combat nutritional deficiencies and be grown widely in tropical and subtropical areas (Bedigian 2004). Sesame is drought-tolerant but highly sensitive to waterlogging caused by poor drainage, flooding, and long periods of rainfall (Ram et al. 1990, Bedigian 2004). The

Submitted 26 October 2018, last revision 22 March 2019, accepted 25 March 2019.

Abbreviations: CB - chlorophyll $a / b$-binding proteins;CS - cysteine synthase; DAP - differentially abundant protein; 2-DE - twodimensional electrophoresis; FBA - fructose-1,6-bisphosphate aldolase; FS - flowering stage; GAPDH - glyceraldehyde-3-phosphate dehydrogenase; HSP - heat shock protein; LS - leaf stage; LTQ-FTICR - linear quadruple trap-Fourier transform ion cyclotron resonance; MDH1 - malate dehydrogenase 1; MS - mass spectrometry; OEE - oxygen-evolving enhancer; RCA - Rubisco activase; ROS - reactive oxygen species; Rubisco - ribulose-1,5-bis-phosphate carboxylase/oxygenase; SAM - S-adenosylmethionine synthetase; SOD - superoxide dismutase; TPI - triosephosphate isomerase.

Acknowledgements: The first two authors have contributed equally to this work.

* Corresponding authors; e-mails: shwoo@chungbuk.ac.kr and chokun@kbsi.re.kr. 
average sesame yield was alarmingly low worldwide in 2011 (http://faostat.fao.org) and this low yield may be attributed to several reasons, but waterlogging is a primary factor in China and Korea.

An adequate supply of soil water is essential for plant growth and for transporting plant nutrients to roots, but excess water in the root zone is a problem for most crops (Kanwar et al. 1988). Soil waterlogging always leads to oxygen deprivation that restricts aerobic respiration in a plant (Fukao and Bailey-Serres 2004). Therefore, prolonged low-oxygen stress results in the enhanced accumulation of reactive oxygen species (ROS), which causes oxidative damage to plant cells (Shabala 2011). Waterlogging, occurring at any growth stage, usually causes degradation of chlorophyll in leaves (Chen et al. 2005, Pociecha et al. 2008) and of protein content in grains (Mishra et al. 2008) and lowers the content of essential nutrient elements in plant shoots (Sharma and Swarup 1988). The effects of waterlogging on the morphological, physiological, and biochemical characteristics of sesame have been investigated during various stages of growth (Sun et al. 2009, Wang et al. 2012, Wei et al. 2013, Saha et al. 2016, Dossa et al. 2017). At the protein level, low oxygen selectively induces the synthesis of anaerobic proteins, especially enzymes involved in sugar metabolism, glycolysis, and fermentation (Huang et al. 2005, Komatsu et al. 2009). The vast majority of these proteins have been investigated in waterlogging susceptible or tolerant strains of Arabidopsis or rice (Bahmanyar 2007, Nakashima et al. 2009, Atkinson et al. 2013).

Proteomics is a high-throughput approach to address gene functions that cannot be elucidated by genome sequences. In addition, proteomic techniques coupled with mass spectrometry (MS) can detect translational and posttranslational regulations of different proteins (Wang et al. 2016b). These techniques have been extensively applied in several crops to explore the mechanisms involved in their response to abiotic stresses (Kosová et al. 2018). Proteins associated with waterlogging tolerance have been reported in maize (Yu et al. 2015), soybean (Alam et al. 2010, Komatsu et al. 2013), wheat (Komatsu et al. 2014) and tomato (Ahsan et al. 2007a,b). More specifically, a number of waterlogging-induced proteins were identified as being involved in photosynthesis, disease- or defense-related mechanisms, metabolic enzymes, molecular chaperones, cell wall biosynthesis, and signaling pathways (Komatsu et al. 2011, 2014, Ghosh and Xu 2014).

A correlation between waterlogging stress-induced physiological and biochemical responses and changes in protein profiles is still lacking. To identify genes of importance, it is imperative to investigate the total proteome expression under waterlogging stress. Despite previous efforts attempting to clarify the mechanisms underlying waterlogging stress at the transcriptional level (Zou et al. 2010, Wang et al. 2012, Thirunavukkarasu et al. 2013, Zhai et al. 2013, Zou et al. 2013, Wang et al. 2016b), it is still unclear how the proteome of sesame respond to this type of stress.

To date, there have been no reports on proteomic studies in combination with physiological and biochemical analyses of sesame plants in response to waterlogging stress. Thus, the present study explored the molecular tolerance mechanisms by which sesame leaves alleviate the adverse effects of waterlogging stress at the flowering and 10-leaf stages through physiological and proteomic analysis. Furthermore, the work was based on the following hypothesis: proteins that reveal differential abundance between waterlogged and untreated plants may play important roles in inducing plant tolerance to waterlogging.

\section{Materials and methods}

Plant growth conditions, waterlogging treatment, and sample collection: The seeds of sesame (Sesamum indicum L., cv. Miryang 44) used in this study were collected from the Rural Development Administration, Korea. Seeds were surface-sterilized with sodium hypochlorite solution $(5 \%, \mathrm{~m} / \mathrm{v})$ for $20 \mathrm{~min}$. Then, seeds were washed with sterile deionized water and then placed into small pots for germination in a controlled environment $\left(25^{\circ} \mathrm{C}\right.$, a $16-\mathrm{h}$ photoperiod, an irradiance of $\left.150 \mu \mathrm{mol} \cdot \mathrm{m}^{-2} \cdot \mathrm{s}^{-1}\right)$ for $7 \mathrm{~d}$. Following germination, the seedlings were transferred to a greenhouse and grown under a 13-h photoperiod, an irradiance of $150 \mu \mathrm{mol} \mathrm{m}^{-2} \mathrm{~s}^{-1}$, day/night temperatures of $28 / 22{ }^{\circ} \mathrm{C}$, and a relative humidity of $70 \%$. Seedlings were grown in plastic pots $(20 \mathrm{~cm}$ in diameter and $30 \mathrm{~cm}$ deep) containing horticultural soil (one plant per pot).

The soil moisture content was measured manually in each pot using a Moisture Meter (WT1000NB RF sensor Seoul, Korea) over the entire experiment. During the 10-leaf stage (10-LS) and flowering stage (FS), the seedlings were subjected to waterlogging conducted by maintaining $2-3 \mathrm{~cm}$ of water above the soil surface for 2 and 3 d. A control experiment was also conducted in parallel. For the physiological and proteomic assays, the leaves from 10-LS and FS were collected from the control and treated seedlings, rinsed with de-ionized water, rapidly frozen in liquid nitrogen, and stored at $-80{ }^{\circ} \mathrm{C}$. Three replicates were carried out for each treatment.

Determination of plant height, stem diameter, and leaf chlorophyll content: To investigate the dynamic morphological alterations, the sesame seedlings were harvested 2 and $3 \mathrm{~d}$ after imposition of waterlogging treatment and the stem diameter and height of the seedlings were measured. In addition, the chlorophyll content of the 10-LS and FS leaves was measured in situ using a $S P A D$ meter (SPAD-502Plus, Konica Minolta, Tokyo, Japan).

Hydrogen peroxide assay: Content of $\mathrm{H}_{2} \mathrm{O}_{2}$ was measured spectrophotometrically as described Kamal et al. (2012). Leaf blades (0.5 g) of 10-LS and FS from the control and treated plants were homogenized with $2 \mathrm{~cm}^{3}$ of $0.1 \%(\mathrm{~m} / \mathrm{v})$ trichloroacetic acid (Junsei Chemical Co., Tokyo, Japan). Then, the homogenate was centrifuged at $12000 \mathrm{~g}$ for $15 \mathrm{~min}$, and a $0.5-\mathrm{cm}^{3}$ aliquot of the supernatant was added to $0.5 \mathrm{~cm}^{3}$ of $10 \mathrm{mM}$ potassium phosphate $\left(\mathrm{K}_{2} \mathrm{HPO}_{4}\right.$ and $\left.\mathrm{KH}_{2} \mathrm{PO}_{4}\right)$ buffer $(\mathrm{pH}$ 7.0) and 
$1 \mathrm{~cm}^{3}$ of $1 \mathrm{M}$ potassium iodide. Absorbance was read at $390 \mathrm{~nm}$. Content of $\mathrm{H}_{2} \mathrm{O}_{2}$ was calculated with a molar coefficient of absorbance $0.28 \mu \mathrm{mol} \mathrm{cm}{ }^{-1}$.

Protein extraction from the 10-LS and FS leaves of the sesame seedling was performed using the trichloroacetoc acid / acetone precipitation method as described Roy et al. (2016). About $500 \mathrm{mg}$ of the frozen leaf tissue was ground into a fine powder in liquid nitrogen. The resulting powder was homogenized in $10 \mathrm{~cm}^{3}$ of ice-cold $10 \%(\mathrm{~m} / \mathrm{v})$ trichloroacetic acid in acetone (100\%) with $0.07 \%(\mathrm{v} / \mathrm{v})$ 2-mercaptoethanol. The homogenate was sonicated for $10 \mathrm{~min}$ followed by incubation at $-20{ }^{\circ} \mathrm{C}$ for $1 \mathrm{~h}$. The resulting precipitate was collected by centrifugation at $9000 \mathrm{~g}$ and $4{ }^{\circ} \mathrm{C}$ for $20 \mathrm{~min}$. Afterward, the pellet was carefully washed twice with ice-cold acetone (100\%) containing $0.07 \%(\mathrm{v} / \mathrm{v}) 2$-mercaptoethanol, centrifuged at $4{ }^{\circ} \mathrm{C}$, and vacuum-dried with Speed-Vac (Modulspin 31, Hanil Science Medical, Seoul, South Korea) for $10 \mathrm{~min}$. The dried sample was suspended in a lysis buffer containing $8 \mathrm{M}$ urea, $2 \mathrm{M}$ thiourea, $5 \%$ (w/v) 3-(3-cholamidopropyl dimethylammonio)-1-propanesulfonate, and $2 \mathrm{mM}$ tri butylphosphine. After incubation at room temperature for $1 \mathrm{~h}$, the suspension was centrifugated at $20000 \mathrm{~g}$ and $25{ }^{\circ} \mathrm{C}$ for $20 \mathrm{~min}$. Finally, protein content was measured according to the method of Bradford (1976) using bovine serum albumin in the lysis buffer as a standard (Bio-Rad, Hercules, USA).

Two-dimensional gel electrophoresis: Sesame leaf proteins were analyzed by two-dimensional gel electrophoresis (2-DE) according to the protocol of O'Farrell (1975). Sample solutions $\left(500 \mathrm{~mm}^{3}\right)$ were loaded onto the acidic side of the iso-electric focusing tube gels $(11 \mathrm{~cm} \times 2 \mathrm{~mm})$, which were pre-run at $150 \mathrm{~V}$ for $1 \mathrm{~h}, 300 \mathrm{~V}$ for $1 \mathrm{~h}$, and $500 \mathrm{~V}$ for $16 \mathrm{~h}$ for the first dimension. Sodium dodecyl sulphate - polyacrylamide gel electrophoresisin the second dimension (Nihon Eido, Tokyo, Japan) was executed with $12 \%(\mathrm{~m} / \mathrm{v})$ separation and $5 \%(\mathrm{~m} / \mathrm{v})$ stacking gels with $13 \mathrm{~cm} \times 13 \mathrm{~cm}$ gel plates. In the second-dimension electrophoresis, the equilibrated strips were placed on the top of the $12 \%(\mathrm{~m} / \mathrm{v})$ SDSpolyacrylamide gels and performed electrophoresis at $35 \mathrm{~mA}$ per gel until the dye front reached the gel bottom.

Protein spots in the 2-DE gels were visualized by Coomassie Brilliant Blue G-250-staining. Two-DE gels were evaluated on an image scanner (HP Scanjet G4010, CA, USA; 300 dpi, 32 bits per pixel). Computer-assisted 2-DE image analysis was performed with the Progenesis SameSpot software (Nonlinear Dynamics, Durham, NC, USA). The volume of each protein spot was normalized relative to the total abundance of all valid spots. A match set was maintained for both control and waterloggingtreated gels (three replicates) after the normalization and background subtraction. A spot was considered to be reproducible when it was present or absent in all replicate gels for each treatment. All gels were matched with one of the selected master gels (a gel image was generated from matched gel sets by the Progenesis SameSpot software). Significant differences in abundance between spots were determined using the Student's $t$-test $(P<0.05)$. Protein spots that changed at least 1.5 -fold at one point in intensity were subjected to MS identification.

In order to in-gel digestion, protein spots were excised from 2-D gels. Subsequently, gel slices were destained with $30 \%(\mathrm{v} / \mathrm{v})$ methanol until the color was completely removed. Then, the gel slices were destained with $10 \mathrm{mM}\left(\mathrm{NH}_{4}\right) \mathrm{HCO}_{3}$ in $50 \%(\mathrm{v} / \mathrm{v})$ acetonitrile, squeezed for 10 min with $100 \%$ acetonitrile, and dried by vacuum centrifugation. After destaining steps, the gel slices were reduced with $10 \mathrm{mM}$ dithiotreitol in $100 \mathrm{mM}$ ammonium bicarbonate at $56{ }^{\circ} \mathrm{C}$ for $1 \mathrm{~h}$ and then alkylated with $55 \mathrm{mM}$ indole-acetic acid in $100 \mathrm{mM}$ ammonium bicarbonate in the dark for $40 \mathrm{~min}$. Then, the proteins were digested with $0.05 \mathrm{~cm}^{3}$ of trypsin buffer and incubated at $37^{\circ} \mathrm{C}$ for $16 \mathrm{~h}$. After digestion, the peptides were extracted with $50 \mathrm{mM}$ ammonium bicarbonate and $0.1 \%(\mathrm{v} / \mathrm{v})$ formic acid in $50 \%(\mathrm{v} / \mathrm{v})$ acetonitrile. The peptide extracts were concentrated by vacuum centrifugation.

Linear quadruple trap-Fourier transform ion cyclotron resonance MS/MS analysis and identification of proteins: All MS experiments for peptide identification were performed on a Nano-LC MS system consisting of a Surveyor HPLC system and a 7-tesla Finningan LTQFTICR mass spectrometer (Thermo Electron, Bremen, Germany) equipped with a nano-ESI source. Each sample $\left(10 \mathrm{~mm}^{3}\right)$ was loaded by a Surveyor autosampler onto a $\mathrm{C}_{18}$ trap column for desalting and concentration at a flow rate of $20 \mathrm{~mm}^{3} \mathrm{~min}^{-1}$. The mass spectrometer was operated in the data-dependent mode to automatically switch between MS and MS acquisition. General MS conditions included a spray voltage of $2.2 \mathrm{kV}$; no sheath and auxiliary gas flow; a ion transfer tube temperature of $220{ }^{\circ} \mathrm{C}$; a collision gas pressure of $1.3 \mathrm{~Pa}$; normalized collision energy using a wide band activation mode; and $35 \%$ after accumulation to a minimum target value of 5000 counts. A ion selection threshold was 500 counts for MS/MS. An activation $\mathrm{q}=0.25$ and an activation time of $30 \mathrm{~ms}$ were applied in MS/MS acquisitions.

The combined MS and MS/MS spectra were searched using Mascot Generic File (MGF) with an in-house licensed Mascot search engine (Mascot v. 2.4.0, Matrix Science, London, UK) against the viridiplantae within the UniProt database (downloaded from Swiss Prot on November 2014; total sequences 547 085; total residues 194742 747). For all the Mascot searches, carbamidomethylation of cysteine was set as a fixed modification while the oxidation of methionine was set as a variable modification. The search parameters allowed a peptide ion tolerance of $100 \mathrm{ppm}$, and a fragment peptide mass tolerance of $2 \mathrm{Da}$. Trypsin was specified as the proteolytic enzyme with one potential missed cleavage. All proteins identified by high-scoring peptides were considered true matches and at least two peptide matches. Protein hits were validated if the identification involved at least 10 top-ranking peptides, and the results were filtered based on a false discovery rate of no more than 0.05 . When those peptides matched multiple members of a protein family, the presented protein was selected based on the highest score and the 
greatest number of matching peptides.

Proteins identified from the present study were grouped into functional categories (Huang et al. 2003) based on gene ontology using data available on the protein information resources (PIR; http://pir.georgetown. edu) as well as literature sources. Identified proteins fold changes were visualized as a heat map at the treatment by waterlogging compared to the control. The heat map was generated by the RStudio software (https://www.rstudio. $\mathrm{com} /$ ).

Statistical analyses: Statistical differences between control and treated samples determined by analysis of variance and the Student's $t$-test at $\alpha=0.05$. At least three independent biological replicates were used. The statistical analysis was performed using the GraphPad Prism 5 software (GraphPad, La Jolla, CA, USA).

\section{Results}

Waterlogging caused a significant inhibition of plant growth at both 10-LS and FS (Fig. 1A). The significant inhibition in plant height (to $85 \mathrm{~cm}$ ) was recorded when the plants were subjected to waterlogging stress for $3 \mathrm{~d}$ at 10-LS whereas plant height exhibited the most considerable reduction (to $99 \mathrm{~cm}$ ) after $3 \mathrm{~d}$ of waterlogging at the FS. Waterlogging also significantly reduced the stem diameter compared to the control plants, and the adverse effects were more pronounced as the duration of waterlogging increased. After $3 \mathrm{~d}$ of waterlogging, stem diameter decreased in 10-LS to $7.9 \mathrm{~mm}$ and in FS to $13.1 \mathrm{~mm}$ (Fig. 1B).

Waterlogging conditions had a negative impact on chlorophyll content in leaf tissue (Fig. 1C). In both 10-LS and FS, the leaf chlorophyll content declined progressively after 2 and $3 \mathrm{~d}$ of waterlogging stress, and the lowest leaf chlorophyll content was observed in waterlogged leaves on day 3. Under waterlogging stress, significant differences were observed in $\mathrm{H}_{2} \mathrm{O}_{2}$ content between 10-LS and FS plants. The $\mathrm{H}_{2} \mathrm{O}_{2}$ content increased gradually in waterlogged leaf samples, and the highest $\mathrm{H}_{2} \mathrm{O}_{2}$ content of $451.7 \mathrm{nmol} \mathrm{g}^{-1}$ (f.m.) was found in 10-LS plants after $3 \mathrm{~d}$ of treatment (Fig. 1D).

A comprehensive leaf proteome was performed to examine molecular characterization in sesame under waterlogging stress during 10-LS and FS. Extracted leaf proteins were separated using 2-DE, and the spot patterns were compared. The intensity of 20 protein spots from the $10-\mathrm{LS}$ and 31 protein spots from the FS differed significantly between the waterlogged and control plants (Fig. 2A-C, Fig. 1 Suppl.). An enlarged image of a few identified gel spots is shown to illustrate the changes observed in the differentially abundant protein (DAP) spots among the groups (Fig. 2). The reproducible protein spots were detected on 2-DE gels in all three biological replicates from the leaves of 10-LS and FS plants (Figs. 2 Suppl. and 3 Suppl.). Only protein spots with fold changes greater than 1.5 or less than $0.66(P<0.05)$ were considered as DAPs. A total of 18 proteins were identified from 10-LS and 29 proteins were identified from FS. However, two proteins were found to be the same from both 10-LS and

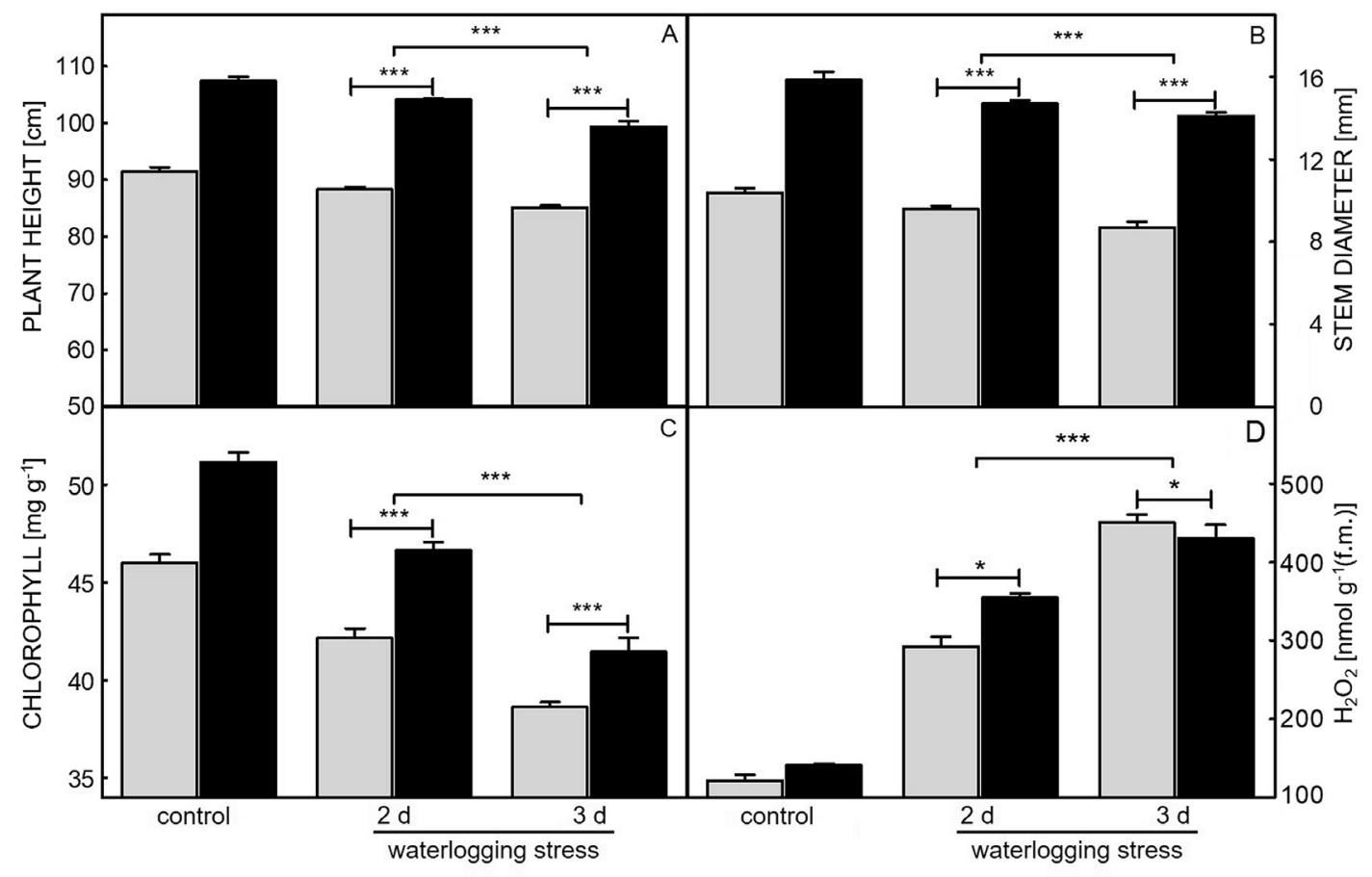

Fig. 1. Morphological and biochemical changes of sesame leaves during waterlogging imposed in the 10-leaf stage (10-LS) and the flowering stage (FS): $A$ - plant height; $B$ - stem diameter; $C$ - chlorophyll content; $D-\mathrm{H}_{2} \mathrm{O}_{2}$ content. Means $\pm \mathrm{SEs}$ for 3 plants. Significant differences between the control and the waterlogging-induced plants were determined by ANOVA and the Student's $t$-test $(*-P \leq 0.05$, $* * *-P \leq 0.001)$. 


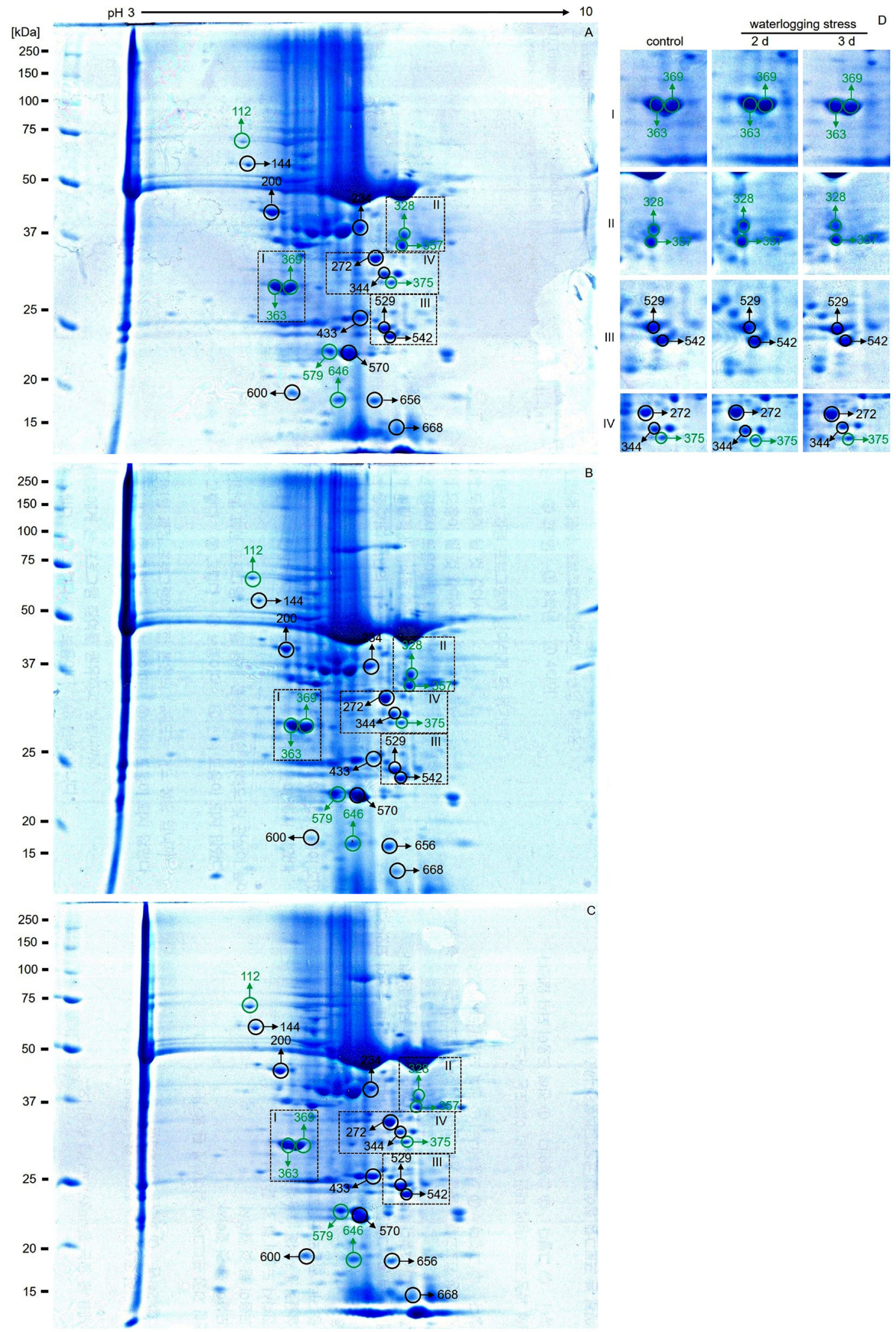

Fig. 2. Representative two-dimensional electrophoresis (2-DE) maps of identified proteins from sesame leaves of the 10-leaf stage plants: $A$ - control; $B$ - waterlogging for $2 \mathrm{~d}$; C - waterlogging for $3 \mathrm{~d}$. An enlarged view of the boxed areas (I, II, III, and IV) shows the difference of 2-DE gel patterns between the waterlogging and control plants. Arrows indicate the differentially abundant proteins in response to waterlogging stress. The differentially abundant protein spots ( $>1.5$-fold difference) are indicated by circles on the 2 -D gel map. These spots were found to be statistically significant at $5 \%$ per group (the Student's $t$-test) using biological and analytical replicates $(n=3)$. A molecular mass of each protein was determined using standard protein markers. 


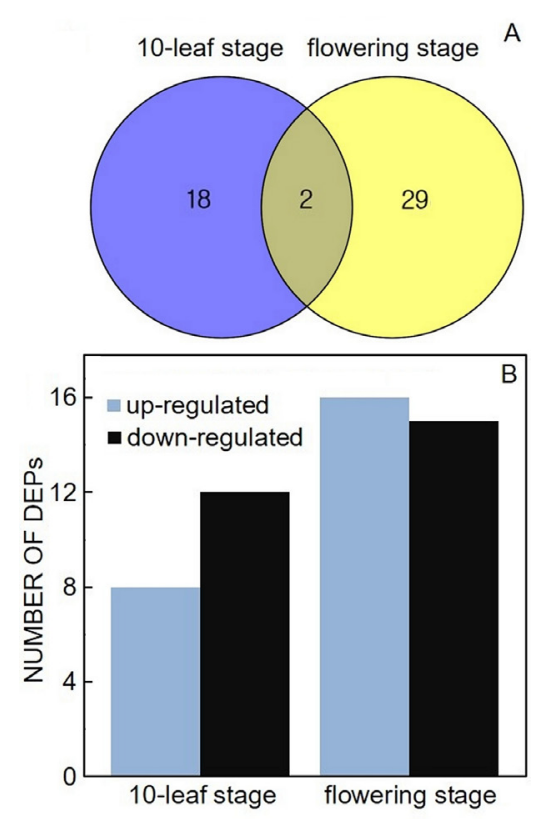

Fig. 3. Expression patterns of proteins of sesame plants at the 10-leaf stage and the flowering stage grown under waterlogging conditions. $A$ - The Venn diagram of differentially abundant proteins. $B$ - The number of differentially abundant proteins.
FS (Fig. 3A). Under waterlogging stress, 20 (8 increased and 12 decreased) protein spots from 10-LS, and 31 (15 increased and 16 decreased) from FS were significantly altered $(P<0.05)$ compared to the control plants (Fig. $3 B)$.

To determine the relative abndance of each protein, a heat map was generated to display the waterloggingresponsive protein fold changes as well as differential protein abundance (Fig. 4). Twenty proteins were displayed in a heat map during waterlogging at 10-LS (Fig. 4A; Table 6 Suppl.). However, during FS, 31 proteins showed differential abundance when the plants were subjected to waterlogging (Fig. 4B; Table 7 Suppl.). In response to waterlogging stress, the heat map shows that several proteins were induced or reduced markedly.

Proteins usually act together in the context of networks in cells rather than exhibiting their functions in an isolated manner (Bian et al. 2015). To explore the relationship among all identified DAPs, protein-protein interactions were analyzed. The interaction evidence of predicted functional protein-protein association networks inferred from 10-LS and FS are shown in the Table 1 Suppl. The STRING database provides a critical assessment and integration of protein-protein interactions including direct (physical) and indirect (functional) associations (Tables 2 Suppl. and 3 Suppl.). The STRING was also

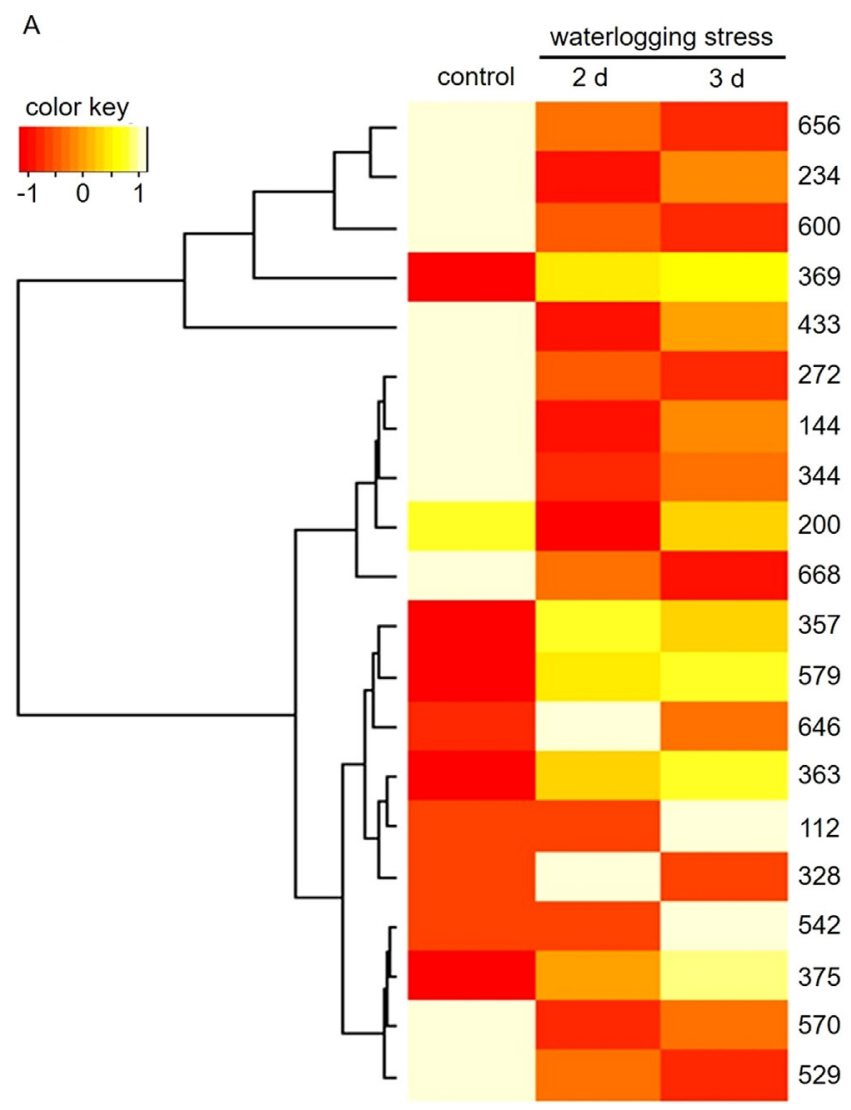

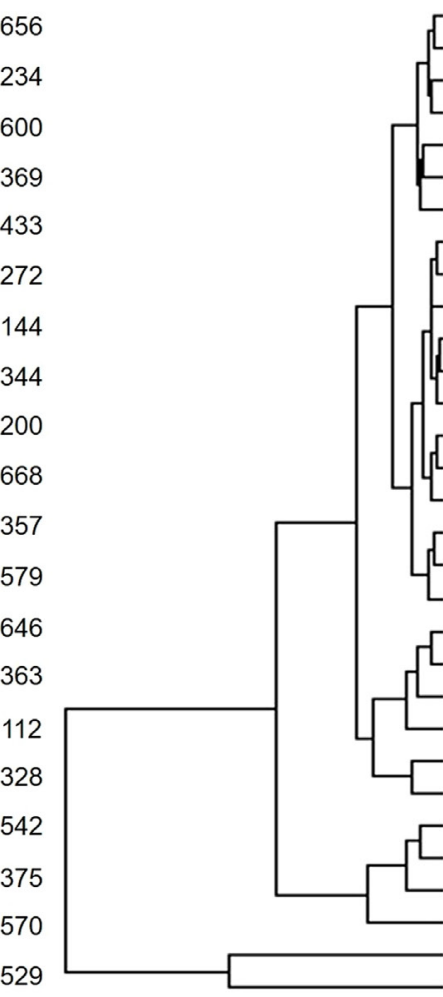

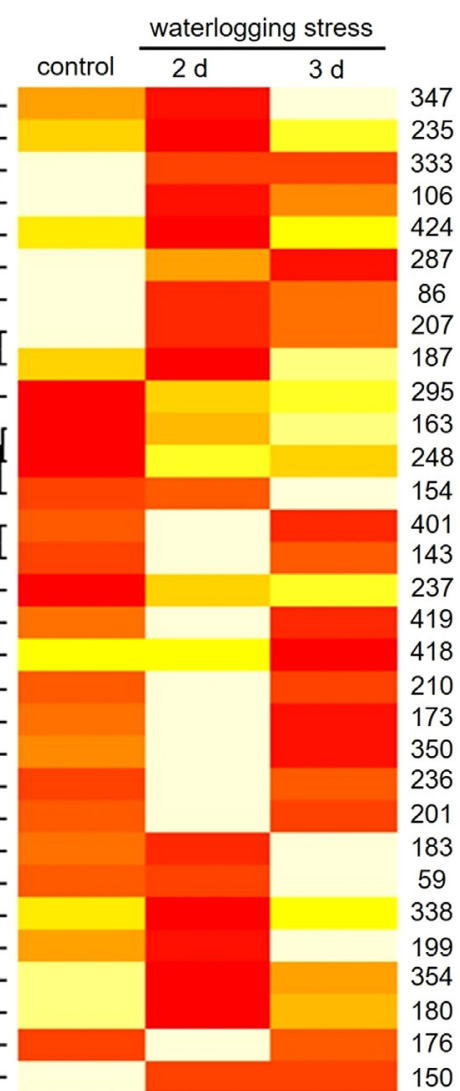

Fig. 4. A heat map displays waterlogging stress-responsive proteins in sesame at the 10-leaf stage $(A)$ and flowering stage $(B)$. Differences in the intensity of labeling associated with the proteins in samples from the control and waterlogging plants are shown as clusters. Any statistically significant difference $(P<0.05)$ in labeling intensity was considered to be positive. The protein spot numbers are indicated on the right side of the cluster. The heat map was generated by the RStudio software. 
used to visualize protein-protein interactions and show the interactions of the identified proteins (Fig. 5).

Six DAPs including S-adenosylmethionine synthetase 1 (SAM1), malate dehydrogenase 1 (MDH1), chaperonin-60, chloroplast heat shock protein 70-1, triosephosphate isomerase (TPI), and fructose-1,6-bisphosphate aldolase 1 (FBA1) in the leaves of sesame during 10-LS and FS were involved in known interaction networks and might perform critical regulatory functions under waterlogging stress. Most energy- and metabolism-related proteins and stress- and defense-related proteins were involved in the protein-protein interaction network. Among them, the energy- and metabolism-related proteins represented the highest proportion $(33.3 \%)$ followed by stress and defense-related proteins $(25 \%)$. More importantly, TPI (spot 433) and MDH1 (spot 199) were the important junctions of interacting proteins in the network suggesting that energy and metabolism were of the utmost importance for response to waterlogging stress (Fig. 5).

Twenty protein spots from 10-LS and 31 from FS that accumulated differentially were analyzed using LTQFTICR. The mass spectra obtained were searched in the UniProt database using the Mascot search engine (Tables 1 and 2). The roles of the identified proteins that were specifically regulated under waterlogging stress were categorized into different functional classes based on their molecular functions, cellular components, and biological processes (Fig. 6A,B).

In 10-LS, the identified proteins were categorized into 10 functional classes according to molecular function. Among them, the larger categories of molecular function accounted for nucleotide binding and ion binding. Regarding subcellular localization, the identified proteins were grouped into seven categories whereas all proteins showed a significant enrichment in plastids followed by membranes and cytoplasm. The DAPs were grouped into 11 different categories according to their biological functions. Most of the proteins identified were photosynthesis-related proteins $(15 \%)$ followed by those related to energy, metabolism, transport, and protein folding. Among the 20 identities from 10-LS, 16 proteins have been functionally annotated in the current database whereas the remaining 4 identities were found as proteins with unknown functions (spots 200, 234, 272, and 579). This analysis indicates that the identified proteins involved in these gene ontology categories might play the most important roles in the regulation of the photosynthesis response to waterlogging stress (Fig. $6 A$ ).

In FS, the identified proteins were categorized into 13 functional classes according to molecular function. Among them, the larger categories of molecular functions accounted for nucleotide binding. According to subcellular localization, the identified proteins were grouped into nine categories whereas all proteins showed a significant enrichment in plastids followed by cytoplasm. According to their biological functions, DAPs were grouped into 15 categories. Most of the proteins identified were from saccharide metabolism (19\%). The remaining proteins were related to stress response $(16 \%)$, amino acid metabolism (6\%), photosynthesis (6\%), RNA processing $(6 \%)$, and protein transport $(6 \%)$ (Fig. 6B). The DAPs during FS involved in these gene ontology categories

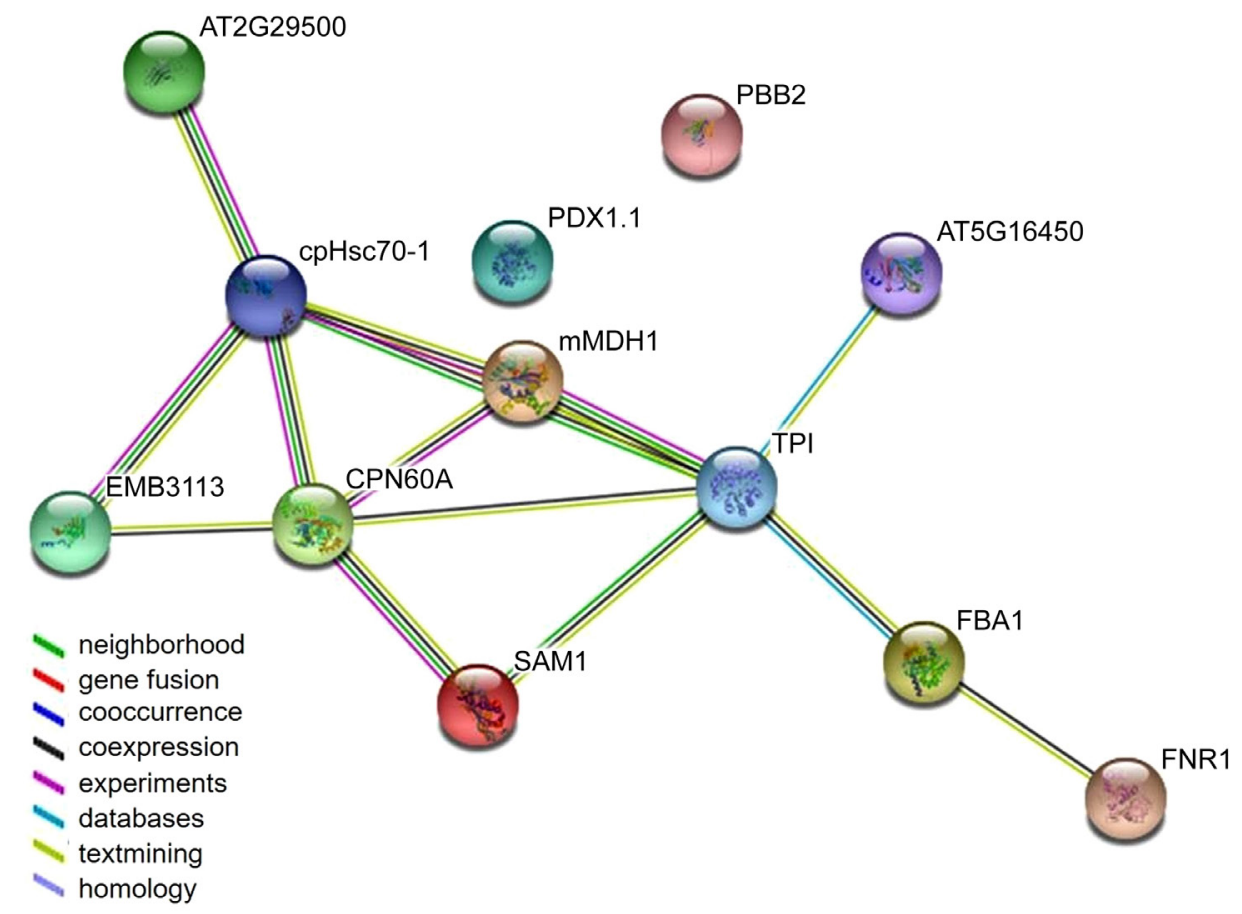

Fig. 5. The interaction network of differentially regulated proteins as analyzed by the STRING software. In this network, nodes are proteins, and lines represent functional associations between proteins. The resulting networks were constructed with confidence scores higher than 0.4 . Network analyzed waterlogging responsive proteins from the 10-leaf and the flowering stages in sesame. The abbreviations of the protein names in the figure are shown in Table 4 Suppl. 


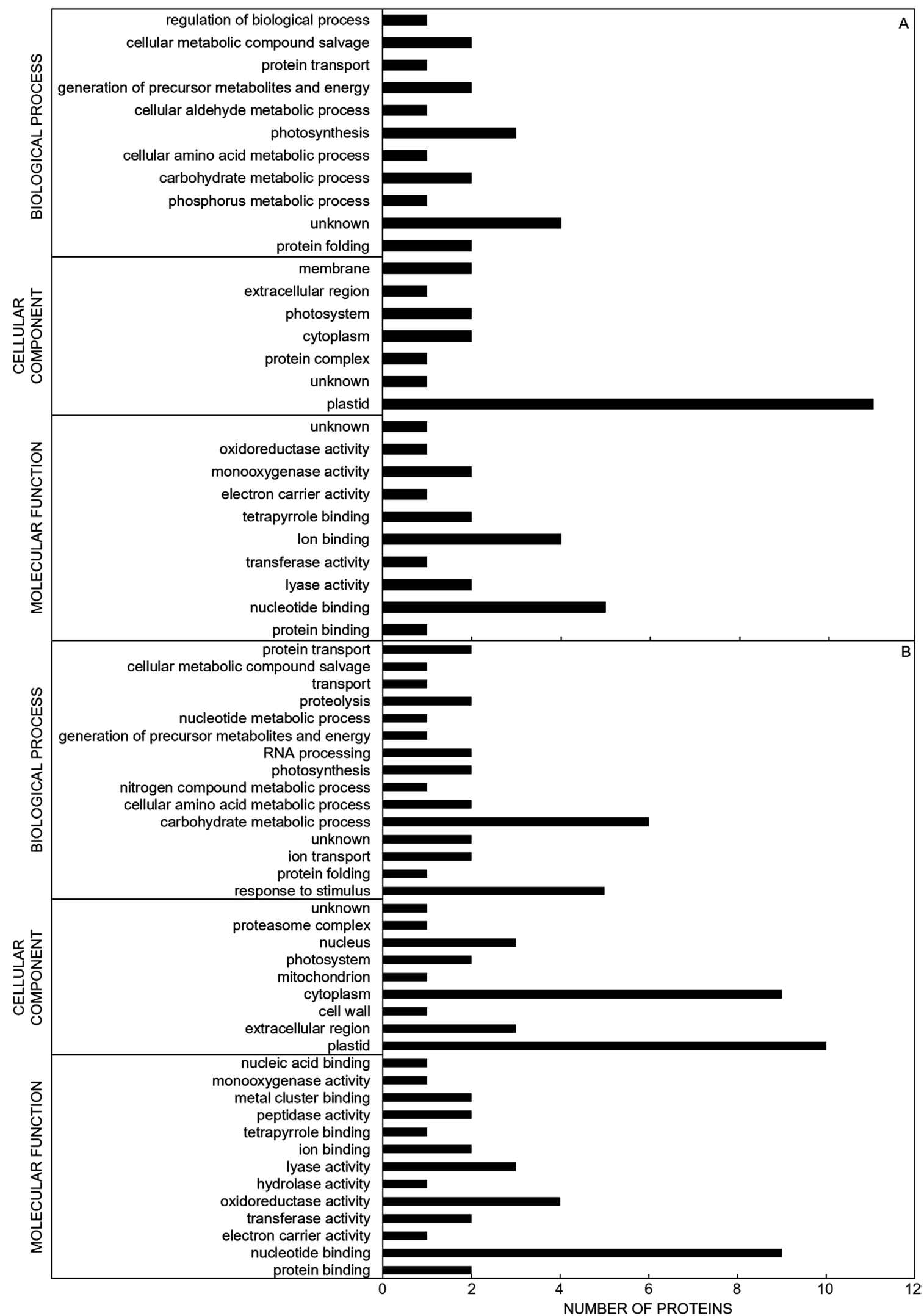

Fig. 6. Frequency distribution of identified proteins within functional categories based on molecular functions, cellular components, and biological processes in sesame at the 10-leaf stage $(A)$ and flowering stage $(B)$ under waterlogging conditions. Classifications were made using iProClass databases, and the assignment of functions was based on gene ontology. 
Table 1. A list of identified proteins from sesame in response to waterlogging during the 10-leaf stage using linear quadruple trap-Fourier transform ion cyclotron resonance mass spectrometry. SN - spot number on the master gel, AN - accession number of the identified proteins regarding the NCBI database, PS - score of the identified peptides, PM - number of matched peptide, the proteins with more than three matched peptides were considered, PC - protein coverage of the identified proteins, Rubisco - ribulose-1,5-bisphosphate carboxylase/oxygenase.

\begin{tabular}{|c|c|c|c|c|c|c|c|}
\hline & AN & Protein description & PS & Exp. Mr/pI & Theor. Mr/pI & PM & $\mathrm{PC}$ \\
\hline \multicolumn{8}{|c|}{ Protein folding } \\
\hline & HSP7S_SPIOL & \multirow{2}{*}{$\begin{array}{l}\text { stromal } 70 \mathrm{kDa} \text { heat shock-related protein } \\
\text { Rubisco large subunit-binding protein subunit } \\
\text { (fragment) }\end{array}$} & 1750 & $64918 / 4.87$ & $64900.46 / 4.87$ & 70 & 19.2 \\
\hline 144 & RUBA_RICCO & & $\alpha_{1540}$ & $51461 / 4.77$ & $52378.84 / 4.77$ & 54 & 31.7 \\
\hline \multicolumn{8}{|c|}{ Phosphorus metabolism process } \\
\hline & ALFC_SPIOL & fructose-bisphosphate aldolase & 248 & $42727 / 6.85$ & $42468.30 / 6.85$ & 20 & 13.5 \\
\hline \multicolumn{8}{|c|}{ Saccharide metabolism } \\
\hline & PGKY_WHEAT & phosphoglycerate kinase & 38 & $42153 / 8.7$ & $42121.96 / 5.64$ & 10 & 8.7 \\
\hline & TPIS_ARATH & triosephosphate isomerase & 61 & $27380 / 5.39$ & $27169.08 / 5.39$ & 4 & 7.1 \\
\hline \multicolumn{8}{|c|}{ Cellular amino acid metabolism } \\
\hline & CYSK_CITLA & cysteine synthase & 93 & $34492 / 6.25$ & $34342.71 / 6.26$ & 3 & 10.8 \\
\hline \multicolumn{8}{|c|}{ Photosynthesis } \\
\hline & PSBO_HELAN & oxygen-evolving enhancer protein 1 & 234 & $34487 / 5.4$ & $34223.66 / 5.40$ & 7 & 15.1 \\
\hline 369 & PSBO_SOLLC & oxygen-evolving enhancer protein 1 & 3876 & $35154 / 5.91$ & $34947.57 / 5.89$ & 138 & 23.1 \\
\hline & UCRIA_SOLTU & cytochrome $b 6-f$ complex iron-sulfur subunit & 351 & $24593 / 8.2$ & $24266.81 / 8.20$ & 27 & 10 \\
\hline \multicolumn{8}{|c|}{ Cellular aldehyde metabolism } \\
\hline & PDX11_ARATH & pyridoxal biosynthesis protein PDX1.1 & 44 & $33126 / 5.75$ & $32861.92 / 5.73$ & 2 & 7.4 \\
\hline \multicolumn{8}{|c|}{ Generation of precursor metabolites and energy } \\
\hline 529 & CB11_SOLLC & chlorophyll $a / b$ binding protein $6 \mathrm{~A}$ & 532 & $26786 / 5.82$ & $26574.67 / 5.83$ & 17 & 14.6 \\
\hline & CB22_HORVU & chlorophyll $a / b$ binding protein 2 & 100 & $28147 / 5.69$ & $28050.97 / 5.69$ & 4 & 9.5 \\
\hline \multicolumn{8}{|c|}{ Protein transport } \\
\hline & YPTC5_CHLRE & GTP-binding protein YPTC5 & 27 & $23470 / 5.73$ & $23142.25 / 5.73$ & 3 & 16.5 \\
\hline \multicolumn{8}{|c|}{ Regulation of biological process } \\
\hline 646 & TRXM_MAIZE & thioredoxin M-type & 30 & $18460 / 8.7$ & $18073.10 / 8.69$ & 2 & 5.4 \\
\hline \multicolumn{8}{|c|}{ Cellular metabolic compound salvage } \\
\hline 656 & RBS_MANES & Rubisco small chain & 1088 & $20625 / 8.65$ & $20410.63 / 8.66$ & 75 & 22 \\
\hline & RBS1_SOYBN & Rubisco small chain 1 & 150 & $20288 / 8.87$ & $20073.36 / 8.87$ & 47 & 25.8 \\
\hline \multicolumn{8}{|c|}{ Unknown } \\
\hline 200 & RCA_ORYSJ & Rubisco activase & 259 & $51764 / 5.43$ & $51454.29 / 5.43$ & 13 & 16.1 \\
\hline 234 & RCA2_LARTR & Rubisco activase 2 & 993 & $48251 / 6.78$ & $48053.85 / 6.78$ & 23 & 23.7 \\
\hline 272 & ALFC1_ARATH & probable fructose-bisphosphate aldolase 1 & 162 & $43075 / 6.18$ & $42930.94 / 6.18$ & 10 & 20.6 \\
\hline 579 & SODCP_SPIOL & superoxide dismutase $[\mathrm{Cu}-\mathrm{Zn}]$ & 3826 & $22667 / 5.88$ & $22567.17 / 5.88$ & 110 & 10.8 \\
\hline
\end{tabular}

may play crucial roles in saccharide metabolism pathway response to waterlogging stress.

\section{Discussion}

Morphological and biochemical changes in response to waterlogging stress: In the present study, waterlogging at both 10-LS and FS adversely affected the morphological and biochemical properties of the leaves leading to alterations in plant height, stem diameter, chlorophyll content, and $\mathrm{H}_{2} \mathrm{O}_{2}$ content. This finding agrees with the findings in soybean (Henshaw et al. 2007) and mung bean (Ahmed et al. 2002). In addition, plant height showed significant differences in cotton after $6 \mathrm{~d}$ of waterlogging at the seedling, squaring, and flowering stages compared to control plants (Wang et al. 2017). The stem after $3 \mathrm{~d}$ of waterlogging was significantly thinner compared with the $2 \mathrm{~d}$ waterlogged and control plants (Fig. $1 B$ ). A previous report demonstrated that waterlogging stress at various developmental stages including FS notably impedes the morphological development of cotton, and waterlogging stress leads to an inhibition in stem diameter and plant height (Reicosky et al. 1985). Taken together, the results 
Table 2. A list of identified proteins from sesame during the flowering stage in response to waterlogging stress using linear quadruple trap-Fourier transform ion cyclotron resonance mass spectrometry (for abbreviations see Table 1).

\begin{tabular}{|c|c|c|c|c|c|c|c|}
\hline SN & AN & Protein description & PS & Exp. Mr/pI & Theor. Mr/pI & PM & $\mathrm{PC}$ \\
\hline \multicolumn{8}{|c|}{ Response to stimulus } \\
\hline 59 & HSP7F_ARATH & heat shock $70 \mathrm{kDa}$ protein 6 & 886 & $76575 / 5.07$ & $76508.02 / 5.07$ & 41 & 22.7 \\
\hline 143 & FNRL1_ARATH & ferredoxin--NADP reductase, leaf isozyme 1 & 550 & $40643 / 8.32$ & $40326.46 / 8.32$ & 18 & 11.1 \\
\hline 154 & METK1_ARATH & S-adenosylmethionine synthase 1 & 688 & $43587 / 5.51$ & $43158.05 / 5.51$ & 30 & 33.8 \\
\hline 199 & MDHM1_ARATH & malate dehydrogenase 1 & 233 & $36010 / 8.54$ & $35804.46 / 8.54$ & 7 & 6.7 \\
\hline 424 & HS17B_ARATH & $17.6 \mathrm{kDa}$ class I heat shock protein 2 & 23 & $17552 / 6.33$ & $17562.82 / 6.33$ & 4 & 15.0 \\
\hline \multicolumn{8}{|c|}{ Protein folding } \\
\hline 86 & CPNA1_ARATH & chaperonin 60 subunit $\alpha 1$ & 44 & $62205 / 5.09$ & $62072.01 / 5.08$ & 5 & 6.5 \\
\hline \multicolumn{8}{|c|}{ Ion transport } \\
\hline 106 & ATPB_PHAAO & ATP synthase subunit beta & 584 & $53998 / 5.44$ & $53974.90 / 5.44$ & 37 & 30.9 \\
\hline & ATPB_BLEOC & ATP synthase subunit beta & 523 & $42392 / 4.94$ & $42417.93 / 4.94$ & 17 & 14.9 \\
\hline \multicolumn{8}{|c|}{ Carbohydrate metabolic process } \\
\hline 163 & PGKY_TOBAC & phosphoglycerate kinase & 443 & $42338 / 5.69$ & $42364.07 / 5.69$ & 28 & 13.5 \\
\hline 173 & KPPR_SPIOL & phosphoribulokinase & 414 & $45321 / 5.82$ & $45007.16 / 5.82$ & 15 & 21.4 \\
\hline 183 & G3PA_PEA & glyceraldehyde-3-phosphate dehydrogenase A & 2229 & $43597 / 8.8$ & $43338.43 / 8.80$ & 61 & 17.0 \\
\hline 187 & G3PC_ANTMA & glyceraldehyde-3-phosphate dehydrogenase & 2009 & $36776 / 8.3$ & $36685.03 / 8.30$ & 81 & 33.2 \\
\hline 201 & G3PC_DIACA & glyceraldehyde-3-phosphate dehydrogenase & 236 & $37105 / 6.46$ & $36900.19 / 6.46$ & 18 & 23.4 \\
\hline 207 & F16P2_SOLTU & fructose-1,6-bisphosphatase & 238 & $37743 / 5.8$ & $37310.62 / 5.80$ & 9 & 7.9 \\
\hline \multicolumn{8}{|c|}{ Cellular amino acid metabolic process } \\
\hline 176 & GLNA1_MEDSA & glutamine synthetase cytosolic isozyme & 3538 & $39254 / 5.49$ & $39107.13 / 5.49$ & 139 & 18.5 \\
\hline 248 & CYSK2_BRAJU & cysteine synthase & 17 & $34225 / 5.51$ & $34132.45 / 5.51$ & 3 & 10.8 \\
\hline \multicolumn{8}{|c|}{ Nitrogen compound metabolic process } \\
\hline 210 & CAS1_MALDO & L-3-cyanoalanine synthase 1 & 181 & $41085 / 7.6$ & $40883.21 / 7.61$ & 17 & 13.6 \\
\hline \multicolumn{8}{|c|}{ Photosynthesis } \\
\hline 235 & PSBO_SOLLC & oxygen-evolving enhancer protein 1 & 41 & $35154 / 5.91$ & $34947.57 / 5.89$ & 5 & 11.2 \\
\hline 237 & PSBO_HELAN & oxygen-evolving enhancer protein 1 & 137 & $34487 / 5.4$ & $34223.66 / 5.40$ & 4 & 13.6 \\
\hline \multicolumn{8}{|c|}{ RNA processing } \\
\hline 236 & RR5_ARATH & 30S ribosomal protein $\mathrm{S} 5$ & 368 & $32682 / 8.99$ & $32645.13 / 8.99$ & 14 & 21.1 \\
\hline 419 & RRAA2_ARATH & putative 4-hydroxy-4-methyl-2-oxoglutarate aldolase 2 & 50 & $18094 / 5.42$ & $17820.36 / 5.42$ & 2 & 6.6 \\
\hline \multicolumn{8}{|c|}{ Generation of precursor metabolites and energy } \\
\hline 287 & CB4B_SOLLC & chlorophyll $a-b$ binding protein CP24 10B & 71 & $27453 / 6.31$ & $27470.53 / 6.31$ & 3 & 7.4 \\
\hline \multicolumn{8}{|c|}{ Nucleotide metabolic process } \\
\hline 295 & KAD4_ORYSJ & adenylate kinase 4 & 78 & $26886 / 7.64$ & $26674.95 / 7.65$ & 6 & 20.2 \\
\hline \multicolumn{8}{|c|}{ Proteolysis } \\
\hline 333 & PSB7B_ARATH & proteasome subunit beta type-7-B & 81 & $29940 / 6.71$ & $29617.00 / 6.71$ & 4 & 6.2 \\
\hline 354 & PSB1_ORYSJ & proteasome subunit beta type- 1 & 109 & $24608 / 6.43$ & $24281.58 / 6.42$ & 4 & 7.2 \\
\hline \multicolumn{8}{|c|}{ Transport } \\
\hline 338 & NDHK_CHAVU & NAD(P)H-quinone oxidoreductase subunit $\mathrm{K}$ & 22 & $27985 / 7.62$ & $27660.74 / 7.61$ & 4 & 22.1 \\
\hline \multicolumn{8}{|c|}{ Cellular metabolic compound salvage } \\
\hline 418 & RBS1_PETHY & ribulose bisphosphate carboxylase small chain SSU8 & 35 & $20585 / 8.29$ & $20370.36 / 8.28$ & 5 & 24.4 \\
\hline \multicolumn{8}{|c|}{ Protein transport } \\
\hline 347 & RANA1_TOBAC & GTP-binding nuclear protein Ran-A1 & 33 & $25345 / 6.38$ & $25018.48 / 6.38$ & 4 & 25.8 \\
\hline 350 & RAN2_ORYSI & GTP-binding nuclear protein Ran-2 & 43 & $25365 / 6.66$ & $25038.65 / 6.65$ & 3 & 19 \\
\hline \multicolumn{8}{|c|}{ Unknown } \\
\hline 150 & RCA2_TOBAC & Rubisco activase 2 & 565 & $48541 / 8.14$ & $48343.09 / 8.14$ & 19 & 23.5 \\
\hline 401 & NDHI_GUATU & $\mathrm{NAD}(\mathrm{P}) \mathrm{H}$-quinone oxidoreductase subunit I & 28 & $19974 / 6.3$ & $19473.67 / 6.30$ & 5 & 26.5 \\
\hline
\end{tabular}


show that waterlogging treatment at different growth stages affected the morphological development of sesame, and the longer the waterlogging duration, the slower the growth.

Waterlogging stress induces stomatal closure leading to the inhibition of $\mathrm{CO}_{2}$ availability in the leaves and, thereby, inhibiting photosynthesis (Crawford 1978). In the present study, chlorophyll content was markedly reduced after plant waterlogging at 10-LS and FS. The decrease in chlorophyll content is thought to be due to acceleration in chlorophyll degradation and/or blocking chlorophyll synthesis when plants are subjected to waterlogging stress. These findings are consistent with previous reports in sesame (Sun et al. 2009, Wang et al. 2012). In addition, a recent report indicated that the low-oxygen conditions caused by waterlogging stress might inhibit chlorophyll synthesis and induce chlorophyll degradation ultimately causing a decrease in chlorophyll content in grapevine (Zhu et al. 2018). Altogether, these results suggest that waterlogging stress in sesame was closely tied to primary photosynthetic processes, and the decrease of photosynthetic activities was associated with chlorophyll loss.

During hypoxia/anoxia, altered redox potential in the cell leads to the production of ROS. Hydrogen peroxide is thought to be increased under different stresses, and it plays an important role as a signaling molecule during stress conditions (Neill et al. 2002, Dat et al. 2003). In the present study, $\mathrm{H}_{2} \mathrm{O}_{2}$ content increased gradually when the plants were subjected to waterlogging stress. However, the content of $\mathrm{H}_{2} \mathrm{O}_{2}$ slightly decreased during FS compared with 10-LS, which might be responsible for the activation of some antioxidant enzymes or any other $\mathrm{H}_{2} \mathrm{O}_{2}$ scavengers (Fig. 1D). The result obtained from the present study is consistent with the findings in tomato leaves under waterlogging stress (Ahsan et al. 2007b). It has been reported that waterlogging stress induces high amounts of $\mathrm{H}_{2} \mathrm{O}_{2}$ in soybean during the early vegetative stage, leading to the initiation of lipid peroxidation with consequent membrane damage (Alam et al. 2010).

Alteration in leaf proteome under waterlogging stress: In this study, we examined proteome changes under waterlogging and control conditions to identify DAPs between the treatment and the control. For proteome analysis, 2-DE was performed, and 51 DAPs were identified from 10-LS and FS in response to waterlogging stress (Fig. 2, Tables 1 and 2, Table 5 Suppl.). The identified proteins can be classified into the following categories according to their biological functions: photosynthesisrelated proteins, energy and metabolism-related proteins, stress and defense-related proteins, metabolism and protein synthesis-related proteins, and some proteins of unknown function.

In the waterlogged sesame plants, many proteins with potential roles in photosynthesis were identified as having a significant response to stress. Among the 11 and 15 categories from 10-LS and FS, the most notable examples were proteins involved in energy and metabolism, stress and defense, and the protein synthesis pathway
(Tables 1 and 2). The possible roles of the identified proteins concerning waterlogging are discussed in the following sections.

Photosynthesis-related proteins: Photosynthesis is an important mechanism that is crucial for synthesis of assimilates and maintaining plant growth; however, this process is sensitive to abiotic stresses (Komatsu et al. 2014). In this study, we found significant changes in key proteins related to the photosynthesis processes. We have identified ribulose-1,5-bisphosphate carboxylase/ oxygenase (Rubisco) small and large subunits (spots 144, 418, 656, and 668), Rubisco activase (RCA, spots 150 , 200 , and 234), oxygen-evolving enhancer proteins (OEE, spots $235,237,363$, and 369), and chlorophyll $a / b$ binding proteins (CB, spots 287, 529, and 542) (Fig. 4 Suppl., Tables 1 and 2).

In the present study, the relative abundance of Rubisco small and large subunits was downregulated. Rubisco is a major photosynthetic protein, and it is also involved in the photorespiratory pathway in plants. Importantly, it is conceived as the key limiting factor of net photosynthesis under stress (Ahsan et al. 2007b, Sang et al. 2017). Down-regulation of the Rubisco-binding protein has been previously reported under flooded conditions (Stoychev et al. 2013). However, it has been documented that the most affected protein caused by different abiotic stresses is the large subunit of Rubisco (Demirevska et al. 2008, Feller et al. 2008, Nakano et al. 2010, Vassileva et al. 2011). The down-regulation of Rubisco due to several environmental stresses has also been reported by other proteomic studies (Nakano et al. 2010). The results obtained in the present study are consistent with these previously published data.

Rubisco activase (spots 150, 200 and 234) is a molecular chaperone that control switching Rubisco from the inactive to active conformation, and it is a key enzyme that affect photosynthesis rate (Spreitzer and Salvucci 2002, Hu et al. 2015). In the present study, the content of RCA was also downregulated under waterlogging stress. Rubisco activase maintains Rubisco in an active state by facilitating the removal of various sugar phosphates that either block substrate binding or prevent carbamylation (Wang and Portis 1992). The content of RCA might be reduced under flooded conditions as previously reported in red and white clover (Stoychev et al. 2013). These findings postulated that the inhibition or degradation of Rubisco or RCA may be one of the major reasons for the decreased photosynthetic rate under waterlogging or other environmental stresses.

Oxygen-evolving enhancer protein 1 plays a role in stabilizing a manganese clusters, the main site of water degradation. Oxygen-evolving enhancer protein 1 proteins can bind four $\mathrm{Mn}^{2+}$ ions that function in chloroplasts in the breakdown of water and maintain an environment for high oxygen rates (Hoganson and Babcock 1997). In the present study, the relative abundance of OEE1 was induced both in 10-LS and in FS in response to waterlogging stress. The previous studies indicated that OEE1 is involved in recovery/turnover, which maintains the capacity of photosystem II under abiotic stresses 
such as salinity and drought (Ngamhui et al. 2012, Fatehi et al. 2013), and waterlogging stress in barley leaves (Luan et al. 2018). Taken together, the present findings suggest that some differentially abundant proteins play a specific role in photosynthesis and might repair protein damage and keep oxygen evolving at both 10-LS and FS in sesame.

Chlorophyll $a / b$-binding proteins are the apoproteins of the light-harvesting complex of photosystem II, which are normally complexed with chlorophylls and xanthophylls and serve as the antenna complex (Jansson 1994). Moreover, the relative abundance of the CB proteins is regulated by multiple environmental stresses including oxidative stress (Staneloni et al. 2008). In the present study, three proteins (CB 2, CB 6A, and CB CP24 $10 \mathrm{~B})$ corresponding to photosynthesis were found to be downregulated during 10-LS and FS under waterlogging stress. The results obtained from the present study are consistent with the findings of Wang et al. (2012). However, a decreased relative abundance of $\mathrm{CB}$ proteins was recorded in soybean seedlings under flooding stress (Hossain and Komatsu 2014). Furthermore, a decreased content of proteins associated with photosynthesis including photosystem components, such as $\mathrm{CB}$ protein in tomato (Tamburino et al. 2017), and rice (Wang et al. 2011), were observed in response to drought stress. Overall, a reduced photosynthesis activity and a low relative abundance of $\mathrm{CB}$ proteins lead to suppression of seedling growth under waterlogging stress.

Energy- and metabolism-related proteins: The energy crisis is a major factor affecting waterlogged plant survival due to aerobic respiration being replaced by anaerobic respiration (Bailey-Serres and Voesenek 2008). Recent investigations revealed that plants induce glycolytic and fermentative enzymes to attain their ATP production during the early adaptive response to waterlogging ( $\mathrm{Yu}$ et al. 2015). Energy- and metabolism-related proteins including fructose-1,6-bisphosphate (spot 207), fructose-1,6bisphosphate aldolase (FBA, spot 328), probable fructose 1,6-bisphosphate aldolase 1 (FBA1, spot 272), ATP synthase subunit $\beta$ (spots 106 and 180), glyceraldehyde3-phosphate dehydrogenase A (GAPDHA, spot 183), cytosolic glyceraldehyde-3-phosphate dehydrogenase (GAPDH, spots 187 and 201), glutamine synthetase cytosolic isozyme (spot 176), and adenylate kinase 4 (spot 295) were upregulated under waterlogging stress (Fig. 4 Suppl., Tables 1, 2).

Fructose-1,6-bisphosphate aldolase is also an essential enzyme involved in glycolysis. It catalyzes a reversible cleavage reaction of fructose-1,6-bisphosphate into two trioses: glyceraldehyde-3-phosphate and dihydroxyacetone phosphate (Matsumoto and Ogawa 2008). In the present study, the quantity of FBA under waterlogging was significantly elevated which may help alleviate the effects of waterlogging stress. The present finding is consistent with the expression profile of this protein in cucumber roots under hypoxic stress (He et al. 2012). A previous study revealed that several enzymes, including FBA, involved in glycolysis significantly accumulated in waterlogged cucumber genotypes suggesting the common regulation of energy generation (Xu et al. 2016).

Adsenosine triphosphate synthase subunits exist in chloroplasts, integrate the thylakoid membrane, and play a key role in energy metabolism and photosynthesis (Wang et al. 2015). A previous report documented that sufficient ATP is crucial when plants are subjected to any environmental stress (Hu et al. 2014). Two proteins associated with ATP synthase were significantly upregulated under waterlogging stress suggesting a higher energy demand for the degradation and biosynthesis of proteins than in the control. These results are similar to those reported in tomato, maize, and cucumber, in which ATP synthase-related proteins show high relative abundances in tolerant plants under waterlogging stress (Ahsan et al. 2007b, Yu et al. 2015, Xu et al. 2016).

Glyceraldehyde-3-phosphate dehydrogenase is an anaerobic peptide, which catalyzes the only reaction in glycolysis in which the oxidation of the substrate is linked directly to the reduction of NAD to NADH. In this study, the accumulation of GAPDH increased under waterlogging stress. However, the homologs of these proteins are found to display a relatively similar behavior under stress conditions. Several studies have revealed that GAPDH accumulation increases under hypoxic conditions in various plant species including potato (Laxalt et al. 1996), maize (Subbaiah and Sachs 2003), and soybean (Nanjo et al. 2011, Mustafa and Komatsu 2014). Taken together, the overexpression of GAPDH played a significant role in assisting sesame to cope with the adverse effects of oxidative stress caused by waterlogging.

Glutamine synthetase is a key enzyme involved in ammonia assimilation in plants, and it catalyzes ATPdependent condensation of ammonia with glutamate to produce glutamine. It has been suggested that the assimilation of nitrate or nitrite may serve as an alternative electron acceptor to oxygen in disposing reducing power generated by glycolysis during anoxia (Weger and Turpin 1989). In this study, glutamine synthetase (spot 176) was abundant only after waterlogging at FS. Enzymes related to glycolytic and fermentative pathways have been confirmed to be induced by waterlogging treatment ( $\mathrm{Yu}$ et al. 2015). Moreover, a previous report revealed that the relative abundance of glutamine synthetase protein is reduced in the roots of cucumber in response to hypoxic conditions (He et al. 2012).

Stress- and defense-related proteins: Plants have developed a complex sensory mechanism to monitor their surroundings and to adapt their growth and development under adverse environmental conditions. Waterlogging induces diverse physiological and biochemical processes in cells (Ahsan et al. 2007b). In the present study, several stress-related proteins were found, including superoxide dismutase [Cu-Zn] (spot 579), stromal $70 \mathrm{kDa}$ heat shockrelated protein (spot 112), thioredoxin M-type (spot 646), heat shock $70 \mathrm{kDa}$ protein 6 (spot 59), chaperonin 60 subunit $\alpha 1$ (spot 86), ferredoxin-NADP reductase, leaf isozyme 1 (spot 143), NAD(P)H-quinone oxidoreductase subunit K (spot 338), NAD(P)H-quinone oxidoreductase subunit I (spot 401), and 17.6 kDa class I heat shock 
protein 2 (spot 424) (Fig. 4 Suppl., Tables 1, 2).

Reactive oxygen species produced in plants experiencing various stresses lead to damage of the normal functions in plant cells (Xu et al. 2016). To protect cells under stress conditions, plants contain several enzymes, including superoxide dismutase (SOD), that scavenge ROS (Lin et al. 2004). In the present study, SOD activity increased after exposure of the sesame plants to waterlogging suggesting that SOD may assist in the reduction of ROS. Previous studies have revealed that the overexpression of SOD significantly enhances tolerance to waterlogging stress in barley (Luan et al. 2018). Several studies have demonstrated that the activities and gene expressions of SOD increase in pigeon pea (Sairam et al. 2009) and mung bean (Sairam et al. 2011) under waterlogging.

Three heat shock proteins (HSPs) were identified in this study. The increased relative abundance of these proteins suggests that they play a crucial role in preventing aggregation of denatured proteins and in facilitating proper folding under stress conditions (Chang et al. 2000, Wang et al. 2004, Ahsan et al. 2007a). Under waterlogging, HSPs show an increased abundance in a tolerant cultivar but remain unchanged in a sensitive cultivar in the leaves and roots of barley (Luan et al. 2018). A wide range of stressrelated proteins including HSPs have been identified in the leaves of tomato whereas the relative abundance of HSPs is induced under waterlogging (Ahsan et al. 2007b). The upregulation of HSPs during flooding has been previously reported and has been found to suppress programmed cell death in maize (Chen et al. 2014).

Chaperones assist in protein folding and assembly (Beckmann et al. 1990) and protect and repair vulnerable proteins under adverse environmental conditions (Qureshi et al. 2007). In addition, HSPs and chaperones are also involved in a wide range of crucial cellular processes (Al-Whaibi 2011). Proteomic analysis in the present study indicates that chaperonin 60 subunit $\alpha 1$, which is involved in stress and defense, was significantly induced in waterlogging-stressed leaves in sesame. The increase of chaperonin 60 subunit $\alpha 1$ in the proteome from flood-treated maize has also been reported (Chen et al. 2014). Our results suggest that an increased abundance of SOD, HSPs, and chaperones would be a protective mechanism towards the instability of proteins in response to waterlogging stress.

Metabolism-related proteins: Waterlogging induced hypoxia is thought to cause rapid changes in gene transcription, protein synthesis and degradation, and cellular metabolism (Christianson et al. 2010). In the present study, several proteins were identified related to metabolism and structural modification including phosphoglycerate kinase (spot 344), TPI (spot 433), GTPbinding protein YPTC5 (spot 570), S-adenosylmethionine synthase 1 (spot 154), phosphoglycerate kinase (spot 163), phosphoribulokinase (spot 173), and malate dehydrogenase 1 (spot 199) (Fig. 4 Suppl. Tables 1, 2).

Phosphoglycerate kinase and TPI are important for ATP-generation and may play crucial roles in the glycolytic pathway (Banks et al. 1979, Cox and Nelson 2000). In this study, the relative abundance of phosphoglycerate kinase and TPI was downregulated in both 10-LS and FS. These results are different from those reported in soybean and grapevine in which phosphoglycerate kinase and TPI showed high relative abundances under flooding stress and water deficiency (Khatoon et al. 2012, Cramer et al. 2013).

S-adenosylmethionine synthetase is an important enzyme that may assist in the synthesis of S-adenosylmethionine and act as a metabolic component in many cellular processes especially in the ethylene synthesis pathway (Yang and Hoffman 1984). In the present study, the relative abundance of SAM was reduced during waterlogging stress. The results obtained from the cucumber roots revealed that SAM is decreased when seedlings are exposed to waterlogging for $2 \mathrm{~d}$ (Xu et al. 2016). Furthermore, SAM is reduced in the proteome in tomato roots under waterlogging stress (Ahsan et al. 2007a). A decreased content of SAM observed in the current study suggests that ethylene production may be impaired by waterlogging stress of sesame.

Malate dehydrogenases, which are essential to the tricarboxylic acid cycle, catalyze the conversion of oxaloacetate to malate (Yao et al. 2011). In the present investigation, the relative abundance of MDH increased in the waterlogged sesame leaves at 10-LS and FS. The relative abundance of $\mathrm{MDH}$ is significantly upregulated in a tolerant barley cultivar in response to waterlogging stress (Luan et al. 2018). Malate dehydrogenase abundance increases in Arabidopsis under osmotic stresses (Ndimba et al. 2005). However, this protein is downregulated in the roots of cucumber (Qi et al. 2012) and soybean (Nanjo et al. 2011) under hypoxic conditions.

Protein biosynthesis and metabolism: Changes in gene expressions and enhanced risk of protein damage induce remarkable alterations in DNA remodeling, transcription, as well as protein degradation (Kosova et al. 2013). Moreover, dramatic changes in protein synthesis have also been previously reported in plants during anaerobiosis. Most of these anaerobic proteins have been identified as enzymes of glycolysis (Sachs et al. 1996). A number of proteins, including cysteine synthase (CS, spots 248 and 357), pyridoxal biosynthesis protein PDX1.1 (spot 375), cytochrome $b 6-f$ complex iron-sulfur subunit (spot 600), and 30S ribosomal protein S5 (spot 236), related to protein degradation/synthesis showed dynamic changes under waterlogging (Fig. 4 Suppl., Tables 1,2).

Cysteine synthase is required for cysteine biosynthesis, which is critical for glutathione production. It has been found that a decreased abundance of CS is correlated with the downregulation of the glutathione content in wheat roots under waterlogging (Biemelt et al. 1998). In the present study, the content of CS was upregulated at 10 -LS. Previous research found that the upregulation of CS may play an important role in plant adaptation to abiotic stress (Shi et al. 2017). The CS related to protein synthesis is found to be more upregulated in primed plants compared with non-primed plants in waterlogged wheat (Wang et al. 2016b). This result suggest that the increased 
abundance of CS corresponded with the higher glutathione content, which contributed to the higher efficiency of ROS scavenging in sesame.

Ribosomal proteins play crucial roles in cell metabolism/division and plant growth and fitness (Whittle and Krochko 2009). Moreover, these proteins generally decrease in plants in response to abiotic stresses (Rogalski et al. 2008). Flooding stress also causes a decrease in the abundance of ribosomal proteins in soybean indicating that ribosomal proteins result in alterations in protein synthesis (Won Oh et al. 2014). In the present study, 30S ribosomal protein S5 decreased in sesame, which might impede protein synthesis in response to waterlogging stress.

A possible waterlogging stress-responsive protein network: In the present study, a waterlogging responsive protein network was proposed based on proteomic analysis (Fig. 5 Suppl.). The synthesis of antioxidant enzymes (SOD) increased to reduce oxidative damage. The instability of proteins caused by the accumulation of ROS notably increased by upregulating of SOD, CS, HSPs, and chaperones to evolve a protective mechanism in response to oxidative stress. Eventually, these proteins might contribute to the higher efficiency of ROS scavenging in sesame. The energy supply increased in the leaves to mitigate waterlogging stress by inducing GS and GAPDH. Moreover, the overexpressions of these energyand metabolism-related proteins provide intrinsic insights into the mechanisms by which sesame copes with the adverse effects of oxidative stress caused by waterlogging. Impaired photosynthesis significantly increased by the upregulation of OEE1 in the leaves.

\section{Conclusions}

In this study, we investigated waterlogging-induced physiological and proteomic responses in sesame at 10LS and FS. The leaf is considered a vital organ that plays a critical role in supplying energy by photosynthesis. The morpho-physiological and proteomic results indicate that the processes of energy metabolism and stress defense were significantly induced under waterlogging. This phenomenon suggests that GS and GAPDH act as key enzymes in sesame leaves under waterlogging, and the associated proteins are important candidate biomarkers for improving waterlogging tolerance in sesame. On the other hand, the photosynthesis-related proteins were reduced during waterlogging. This finding suggests that sustained waterlogging stress of sesame affects photosynthesis in leaves. Further investigations including functional analyses, transcriptomic, proteomic, and metabolomic evaluations of these candidate genes are required to elucidate the comprehensive molecular networks of sesame in response to waterlogging. In addition, a comparative study between sensitive and tolerant cultivars would be an avenue for further elucidation of the response pathway of waterlogging stress in sesame.

\section{References}

Aggarwal, P.K., Kalra, N., Chander, S., Pathak, H.: InfoCrop: a dynamic simulation model for the assessment of crop yields, losses due to pests, and environmental impact of agroecosystems in tropical environments. I. Model description. Agr. Syst. 89: 1-25, 2006.

Ahmed, S., Nawata, E., Sakuratani, T.: Effects of waterlogging at vegetative and reproductive growth stages on photosynthesis, leaf water potential and yield in mungbean. - Plant Prod. Sci. 5: 117-123, 2002.

Ahsan, N., Lee, D.-G., Lee, S.-H., Lee, K.-W., Bahk, J.D., Lee, B.-H.: A proteomic screen and identification of waterloggingregulated proteins in tomato roots. - Plant Soil 295: 37-51, $2007 \mathrm{a}$.

Ahsan, N., Lee, D.G., Lee, S.H., Kang, K.Y., Bahk, J.D., Choi, M.S., Lee, I.J., Renaut, J., Lee, B.H.: A comparative proteomic analysis of tomato leaves in response to waterlogging stress. Physiol Plant 131: 555-570, 2007b.

Al-Whaibi, M.H.: Plant heat-shock proteins: a mini review. - J. King Saud Univ. Sci. 23: 139-150, 2011.

Alam, I., Lee, D.G., Kim, K.H., Park, C.H., Sharmin, S.A., Lee, H., Oh, K.W., Yun, B.W., Lee, B.H.: Proteome analysis of soybean roots under waterlogging stress at an early vegetative stage. - J. Biosci. 35: 49-62, 2010.

Atkinson, N.J., Lilley, C.J., Urwin, P.E.: Identification of genes involved in the response of Arabidopsis to simultaneous biotic and abiotic stresses. - Plant Physiol. 162: 2028-2041, 2013.

Bahmanyar, M.A. The influence of continuous rice cultivation and different waterlogging periods on morphology, clay mineralogy, Eh, pH, and K in paddy soils. - Pak. J. biol. Sci. 10: 2844-2849, 2007.

Bailey-Serres, J., Fukao, T., Gibbs, D.J., Holdsworth, M.J., Lee, S.C., Licausi, F., Perata, P., Voesenek, L.A.C.J., Van Dongen, J.T.: Making sense of low oxygen sensing. Trends Plant Sci. 17: 129-138, 2012.

Bailey-Serres, J., Voesenek, L.A.C.J.: Flooding stress: acclimations and genetic diversity. - Annu. Rev. Plant Biol. 59: 313-339, 2008.

Banks, R.D., Blake, C.C., Evans, P.R., Haser, R., Rice, D.W., Hardy, G.W., Merrett, M., Phillips, A.W.: Sequence, structure and activity of phosphoglycerate kinase: a possible hingebending enzyme. - Nature 279: 773-777, 1979.

Beckmann, R., Mizzen, L., Welch, W.: Interaction of Hsp 70 with newly synthesized proteins: implications for protein folding and assembly. - Science 248: 850-854, 1990.

Bedigian, D.: History and lore of sesame in Southwest Asia. Econom. Bot. 58: 330-353, 2004.

Bian, Y.-W., Lv, D.-W., Cheng, Z.-W., Gu, A.-Q., Cao, H., Yan, Y.-M.: Integrative proteome analysis of Brachypodium distachyon roots and leaves reveals a synergetic responsive network under $\mathrm{H}_{2} \mathrm{O}_{2}$ stress. - J. Proteom. 128: 388-402, 2015.

Biemelt, S., Keetman, U., Albrecht, G.: Re-aeration following hypoxia or anoxia leads to activation of the antioxidative defense system in roots of wheat seedlings. - Plant Physiol. 116: 651-658, 1998.

Bradford, M.M.: A rapid and sensitive method for the quantitation of microgram quantities of protein utilizing the principle of protein-dye binding. - Anal. Biochem. 72: 248-254, 1976.

Chang, W.W.P., Huang, L., Shen, M., Webster, C., Burlingame, A.L., Roberts, J.K.M.: Patterns of protein synthesis and tolerance of anoxia in root tips of maize seedlings acclimated to a low-oxygen environment, and identification of proteins by mass spectrometry. - Plant Physiol. 122: 295-318, 2000.

Chen, H., Qualls, R., Blank, R.: Effect of soil flooding on 
photosynthesis, carbohydrate partitioning and nutrient uptake in the invasive exotic Lepidium latifolium. - Aquat. Bot. 82: 250-268, 2005.

Chen, Y., Chen, X., Wang, H., Bao, Y., Zhang, W.: Examination of the leaf proteome during flooding stress and the induction of programmed cell death in maize. - Proteome Sci. 12: 3333, 2014

Christianson, J.A., Llewellyn, D.J., Dennis, E.S., Wilson, I.W.: Global gene expression responses to waterlogging in roots and leaves of cotton (Gossypium hirsutum L.). - Plant Cell Physiol. 51: 21-37, 2010.

Cox, M., Nelson, D.: Lehninger Principles of Biochemistry. W.H. Freeman and Company, New York 2008.

Cramer, G.R., Van Sluyter, S.C., Hopper, D.W., Pascovici, D., Keighley, T., Haynes, P.A.: Proteomic analysis indicates massive changes in metabolism prior to the inhibition of growth and photosynthesis of grapevine (Vitis vinifera $\mathrm{L}$.) in response to water deficit. - BMC Plant Biol. 13: 49-49, 2013.

Crawford, R.M.M.: Metabolic adaptation to anoxia. - In: Hook, D.D., Crawford, R.M.M. (ed.): Plant Life in Anaerobic Environments. Pp. 119-136. Ann Arbor Science, Ann Arbor 1978.

Dat, J.F., Pellinen, R., Van De Cotte, B., Langebartels, C., Kangasjärvi, J., Inzé, D., Van Breusegem, F.: Changes in hydrogen peroxide homeostasis trigger an active cell death process in tobacco. - Plant J. 33: 621-632, 2003.

Demirevska, K., Simova-Stoilova, L., Vassileva, V., Feller, U.: Rubisco and some chaperone protein responses to water stress and rewatering at early seedling growth of drought sensitive and tolerant wheat varieties -. Plant Growth Regul. 56: 97, 2008.

Dossa, K., Li, D., Wang, L., Zheng, X., Liu, A., Yu, J., Wei, X., Zhou, R., Fonceka, D., Diouf, D., Liao, B.: Transcriptomic, biochemical and physio-anatomical investigations shed more light on responses to drought stress in two contrasting sesame genotypes. - Sci. Rep. 7: 8755-8755, 2017.

Fatehi, F., Hosseinzadeh, A., Alizadeh, H., Brimavandi, T.: The proteome response of Hordeum spontaneum to salinity stress. - Cereal Res. Commun. 41: 78-87, 2013.

Feller, U., Anders, I., Demirevska, K.: Degradation of Rubisco and other chloroplast proteins under abiotic stress. - Gen. appl. Plant Physiol. 34: 5-18, 2008.

Fukao, T., Bailey-Serres, J.: Plant responses to hypoxia-is survival a balancing act? - Trends Plant Sci. 9: 449-456, 2004.

Ghosh, D., Xu, J.: Abiotic stress responses in plant roots: a proteomics perspective. - Front. Plant Sci. 5: 6, 2014

He, L., Lu, X., Tian, J., Yang, Y., Li, B., Li, J., Guo, S.: Proteomic analysis of the effects of exogenous calcium on hypoxicresponsive proteins in cucumber roots. - Proteome Sci. 10: 42-42, 2012.

Henshaw, T., Gilbert, R., Scholberg, J., Sinclair, T.: Soya bean (Glycine $\max$ L. Merr.) genotype response to early-season flooding: II. Aboveground growth and biomass. - J. Agron. Crop Sci. 193: 189-197, 2007.

Hoganson, C.W., Babcock, G.T.: A metalloradical mechanism for the generation of oxygen from water in photosynthesis. Science 277: 1953-1956, 1997.

Hossain, Z., Komatsu, S.: Potentiality of soybean proteomics in untying the mechanism of flood and drought stress tolerance. - Proteomes 2: 107-127, 2014.

Hu, W. J., Chen, J., Liu, T.W., Wu, Q., Wang, W.H., Liu, X., Shen, Z.J., Simon, M., Wu, F.H., Pei, Z.M.: Proteome and calcium-related gene expression in Pinus massoniana needles in response to acid rain under different calcium levels. - Plant Soil 380: 285-303, 2014.

Hu, W.J., Wu, Q., Liu, X., Shen, Z.J., Chen, J., Liu, T.W., Zhu,
C.Q., Wu, F.H., Chen, L.: Comparative proteomic analysis reveals the effects of exogenous calcium against acid rain stress in Liquidambar formosana Hance leaves. - J. Proteome Res. 15: 216-228, 2015.

Huang, H., Barker, W.C., Chen, Y., Wu, C.H.: iProClass: an integrated database of protein family, function and structure information. - Nucl. Acids Res. 31: 390-392, 2003.

Huang, S., Greenway, H., Colmer, T.D., Millar, A.H.: Protein synthesis by rice coleoptiles during prolonged anoxia: implications for glycolysis, growth and energy utilization. Ann. Bot. 96: 703-715, 2005.

Jansson, S.: The light-harvesting chlorophyll $a b$-binding proteins. - Biochim. biophys. Acta Bioenerg. 1184: 1-19, 1994.

Kamal, A.H.M., Cho, K., Kim, D.E., Uozumi, N., Chung, K.Y., Lee, S.Y., Choi, J.S., Cho, S.W., Shin, C.S., Woo, S.H.: Changes in physiology and protein abundance in salt-stressed wheat chloroplasts. - Mol. Biol. Rep. 39: 9059-9074, 2012.

Kanwar, S., Baker, J.L., Mukhtar, S.: Excessive soil water effects at various stages of development on the growth and yield of corn. - Trans ASAE 31: 133-0141, 1988.

Khatoon, A., Rehman, S., Salavati, A., Komatsu, S.: A comparative proteomics analysis in roots of soybean to compatible symbiotic bacteria under flooding stress. - Amino Acids 43: 2513-2525, 2012.

Komatsu, S., Hiraga, S., Yanagawa, Y.: Proteomics techniques for the development of flood tolerant crops. - J. Proteome Res. 11: 68-78, 2011.

Komatsu, S., Kamal, A.H., Hossain, Z.: Wheat proteomics: proteome modulation and abiotic stress acclimation. - Front. Plant Sci. 5: 684, 2014

Komatsu, S., Shirasaka, N., Sakata, K.: 'Omics' techniques for identifying flooding-response mechanisms in soybean. - J. Proteom. 93: 169-178, 2013.

Komatsu, S., Yamamoto, R., Nanjo, Y., Mikami, Y., Yunokawa, H., Sakata, K.: A comprehensive analysis of the soybean genes and proteins expressed under flooding stress using transcriptome and proteome techniques. - J. Proteome Res. 8: 4766-4778, 2009.

Kosová, K., Prášil, I.T., Vítámvás, P.: Protein contribution to plant salinity response and tolerance acquisition. - Int. J. mol. Sci. 14: 6757-6789, 2013.

Kosová, K., Vítámvás, P., Urban, M.O., Prášil, I.T., Renaut, J.: Plant abiotic stress proteomics: the major factors determining alterations in cellular proteome. - Front. Plant Sci. 9: 122, 2018.

Laxalt, A.M., Cassia, R.O., Sanllorenti, P.M., Madrid, E.A., Andreu, A.B., Daleo, G.R., Conde, R.D., Lamattina, L.: Accumulation of cytosolic glyceraldehyde-3-phosphate dehydrogenase RNA under biological stress conditions and elicitor treatments in potato. - Plant mol. Biol. 30: 961-972, 1996.

Lin, K.H.R., Weng, C.C., Lo, H.F., Chen, J.T.: Study of the root antioxidative system of tomatoes and eggplants under waterlogged conditions. - Plant Sci. 167: 355-365, 2004.

Luan, H., Shen, H., Pan, Y., Guo, B., Lv, C., Xu, R.: Elucidating the hypoxic stress response in barley (Hordeum vulgare L.) during waterlogging: A proteomics approach. - Sci. Rep. 8: 9655, 2018.

Matsumoto, M., Ogawa, K.I.: New insight into the Calvin cycle regulation-glutathionylation of fructose bisphosphate aldolase in response to illumination. - In: Allen, J.F., Gantt, E., Golbeck, J.H., Osmond, B. (ed): Photosynthesis Energy from the Sun. Pp. 871-874. Springer, Dordrecht 2008.

Mishra, S., Patro, L., Mohapatra, P., Biswal, B.: Response of senescing rice leaves to flooding stress. - Photosynthetica 46: 315, 2008. 
Mustafa, G., Komatsu, S.: Quantitative proteomics reveals the effect of protein glycosylation in soybean root under flooding stress. - Front. Plant Sci. 5: 627, 2014.

Nakano, R., Ishida, H., Kobayashi, M., Makino, A., Mae, T.: Biochemical changes associated with in vivo RbcL fragmentation by reactive oxygen species under chilling-light conditions. - Plant Biol. 12: 35-45, 2010.

Nakashima, K., Ito, Y., Yamaguchi-Shinozaki, K.: Transcriptional regulatory networks in response to abiotic stresses in Arabidopsis and grasses. - Plant Physiol. 149: 88-95, 2009.

Nanjo, Y., Maruyama, K., Yasue, H., Yamaguchi-Shinozaki, K., Shinozaki, K., Komatsu, S.: Transcriptional responses to flooding stress in roots including hypocotyl of soybean seedlings. - Plant mol. Biol. 77: 129-144, 2011.

Ndimba, B.K., Chivasa, S., Simon, W.J., Slabas, A.R.: Identification of Arabidopsis salt and osmotic stress responsive proteins using two-dimensional difference gel electrophoresis and mass spectrometry. - Proteomics 5: 4185-4196, 2005.

Neill, S., Desikan, R., Hancock, J.: Hydrogen peroxide signalling. - Curr. Opin. Plant Biol. 5: 388-395, 2002.

Ngamhui, N.-O., Akkasaeng, C., Zhu, Y.J., Tantisuwichwong, N., Roytrakul, S., Sansayawichai, T.: Differentially expressed proteins in sugarcane leaves in response to water deficit stress. - Plant Omics 5: 365, 2012.

O'Farrell, P.H.: High resolution two-dimensional electrophoresis of proteins. - J. biol. Chem. 250: 4007-4021, 1975.

Pociecha, E., Kościelniak, J., Filek, W.: Effects of root flooding and stage of development on the growth and photosynthesis of field bean (Vicia faba L. minor). - Acta Physiol. Plant. 30: $529,2008$.

Qi, X.H., Xu, X.W., Lin, X.J., Zhang, W.J., Chen, X.H.: Identification of differentially expressed genes in cucumber (Cucumis sativus L.) root under waterlogging stress by digital gene expression profile. - Genomics 99: 160-168, 2012.

Qureshi, M.I., Qadir, S., Zolla, L.: Proteomics-based dissection of stress-responsive pathways in plants. - J. Plant Physiol. 164: 1239-1260, 2007.

Ram, R., Catlin, D., Romero, J., Cowley, C.: Sesame: new approaches for crop improvemen.t - In: Janick, J., Simon, J.E. (ed.):: Advances in New Crops. Pp. 225-228. Timber Press, Portland 1990.

Reicosky, D., Meyer, W., Schaefer, N., Sides, R.: Cotton response to short-term waterlogging imposed with a water-table gradient facility. - Agr. Water Manage. 10: 127-143, 1985.

Rogalski, M., Schöttler, M.A., Thiele, W., Schulze, W.X., Bock, R.: Rpl33, a nonessential plastid-encoded ribosomal protein in tobacco, is required under cold stress conditions. - Plant Cell 20: 2221-2237, 2008.

Roy, S.K., Kwon, S.J., Cho, S.W., Kamal, A.H.M., Kim, S.W., Sarker, K., Oh, M.W., Lee, M.S., Chung, K.Y., Xin, Z.: Leaf proteome characterization in the context of physiological and morphological changes in response to copper stress in sorghum. - BioMetals 29: 495-513, 2016.

Sachs, M.M., Subbaiah, C.C., Saab, I.N.: Anaerobic gene expression and flooding tolerance in maize. - J. exp. Bot. 47: $1-15,1996$.

Saha, R., Ahmed, F., Mokarroma, N., Rohman, M., Golder, P.: Physiological and biochemical changes in waterlogging tolerant sesame genotypes. - SAARC J. Agr. 14: 31-45, 2016.

Sairam, R., Kumutha, D., Ezhilmathi, K., Chinnusamy, V., Meena, R.: Waterlogging induced oxidative stress and antioxidant enzyme activities in pigeon pea. - Biol. Plant. 53: 493-504, 2009.

Sairam, R.K., Dharmar, K., Lekshmy, S., Chinnusamy, V.: Expression of antioxidant defense genes in mung bean (Vigna radiata L.) roots under water-logging is associated with hypoxia tolerance -. Acta Physiol. Plant. 33: 735-744, 2011.

Sang, Q., Shan, X., An, Y., Shu, S., Sun, J., Guo, S.: Proteomic analysis reveals the positive effect of exogenous spermidine in tomato seedlings' response to high-temperature stress. Front. Plant Sci. 8: 120, 2017.

Shabala, S.: Physiological and cellular aspects of phytotoxicity tolerance in plants: the role of membrane transporters and implications for crop breeding for waterlogging tolerance. New Phytol. 190: 289-298, 2011.

Sharma, D., Swarup, A.: Effects of short-term flooding on growth, yield and mineral composition of wheat on sodic soil under field conditions. - Plant Soil 107: 137-143, 1988.

Shi, J., Chen, Y., Xu, Y., Ji, D., Chen, C., Xie, C.: Differential proteomic analysis by iTRAQ reveals the mechanism of Pyropia haitanensis responding to high temperature stress. Sci. Rep. 7: 44734, 2017.

Spreitzer, R.J., Salvucci, M.E.: Rubisco: structure, regulatory interactions, and possibilities for a better enzyme. - Annu. Rev. Plant Biol. 53:449-475, 2002.

Staneloni, R.J., Rodriguez-Batiller, M.J., Casal, J.J.: Abscisic acid, high-light, and oxidative stress down-regulate a photosynthetic gene via a promoter motif not involved in phytochrome-mediated transcriptional regulation. - Mol. Plant 1: 75-83, 2008.

Stoychev, V., Simova-Stoilova, L., Vaseva, I., Kostadinova, A., Nenkova, R., Feller, U., Demirevska, K.: Protein changes and proteolytic degradation in red and white clover plants subjected to waterlogging. - Acta Physiol. Plant. 35: 19251932, 2013.

Subbaiah, C.C., Sachs, M.M.: Molecular and cellular adaptations of maize to flooding stress. - Ann. Bot. 91: 119-127, 2003.

Sun, J., Zhang, X., Zhang, Y., Wang, L., Huang, B.: Effects of waterlogging on leaf protective enzyme activities and seed yield of sesame at different growth stages. - Chin. J. appl. environ. Biol. 15: 790-795, 2009.

Tamburino, R., Vitale, M., Ruggiero, A., Sassi, M., Sannino, L., Arena, S., Costa, A., Batelli, G., Zambrano, N., Scaloni, A.: Chloroplast proteome response to drought stress and recovery in tomato (Solanum lycopersicum L.). - BMC Plant Biol. 17: 40, 2017.

Thirunavukkarasu, N., Hossain, F., Mohan, S., Shiriga, K., Mittal, S., Sharma, R., Singh, R.K., Gupta, H.S.: Genome-wide expression of transcriptomes and their co-expression pattern in subtropical maize (Zea mays L.) under waterlogging stress. - PLoS ONE 8: e70433, 2013.

Vassileva, V., Demirevska, K., Simova-Stoilova, L., Petrova, T., Tsenov, N., Feller, U.: Winter wheat cultivars under longterm field drought-biochemical and ultrastructural constraints affecting yield. - J. Agron. Crop Sci. 198: 104-117, 2011.

Wang, D., Pan, Y., Zhao, X., Zhu, L., Fu, B., Li, Z.: Genomewide temporal-spatial gene expression profiling of drought responsiveness in rice. - BMC Genomics 12: 149, 2011.

Wang, L., Li, D., Zhang, Y., Gao, Y., Yu, J., Wei, X., Zhang, $\mathrm{X}$. : Tolerant and susceptible sesame genotypes reveal waterlogging stress response patterns. - PLoS ONE 11: e0149912, 2016a.

Wang, L., Zhang, Y., Qi, X., Li, D., Wei, W., Zhang, X.: Global gene expression responses to waterlogging in roots of sesame (Sesamum indicum L.). - Acta Physiol. Plant. 34: 2241-2249, 2012.

Wang, N., Zhao, J., He, X., Sun, H., Zhang, G., Wu, F.: Comparative proteomic analysis of drought tolerance in the two contrasting Tibetan wild genotypes and cultivated genotype. - BMC Genomics 16: 432, 2015.

Wang, W., Vinocur, B., Shoseyov, O., Altman, A.: Role of plant heat-shock proteins and molecular chaperones in the abiotic 
stress response. - Trends Plant Sci. 9: 244-252, 2004.

Wang, X., Deng, Z., Zhang, W., Meng, Z., Chang, X., Lv, M.: Effect of waterlogging duration at different growth stages on the growth, yield and quality of cotton. - PLoS ONE 12: e0169029: 2017

Wang, X., Huang, M., Zhou, Q., Cai, J., Dai, T., Cao, W., Jiang, D.: Physiological and proteomic mechanisms of waterlogging priming improves tolerance to waterlogging stress in wheat (Triticum aestivum L.). - Environ. exp. Bot. 132: 175-182, 2016b.

Wang, Z.Y., Portis, A.R.: Dissociation of ribulose-1,5bisphosphate bound to ribulose-1,5-bisphosphate carboxylase/ oxygenase and its enhancement by ribulose-1,5-bisphosphate carboxylase/oxygenase activase-mediated hydrolysis of ATP. - Plant Physiol. 99: 1348-1353, 1992.

Weger, H.G., Turpin, D.H.: Mitochondrial respiration can support $\mathrm{NO}_{3}{ }^{-}$and $\mathrm{NO}_{2}^{-}$reduction during photosynthesis: interactions between photosynthesis, respiration, and $\mathrm{N}$ assimilation in the N-limited green alga Selenastrum minutum. - Plant Physiol. 89: 409-415, 1989.

Wei, W., Li, D., Wang, L., Ding, X., Zhang, Y., Gao, Y., Zhang, X.: Morpho-anatomical and physiological responses to waterlogging of sesame (Sesamum indicum L.). - Plant Sci. 208: 102-111, 2013.

Whittle, C.A., Krochko, J.E.: Transcript profiling provides evidence of functional divergence and expression networks among ribosomal protein gene paralogs in Brassica napus. Plant Cell 21: 2203-2219, 2009.

Won Oh, M., Nanjo, Y., Komatsu, S.: Identification of nuclear proteins in soybean under flooding stress using proteomic technique. - Protein Peptide Lett. 21: 458-467, 2014.

Xu, X., Ji, J., Ma, X., Xu, Q., Qi, X., Chen, X.: Comparative proteomic analysis provides insight into the key proteins involved in cucumber (Cucumis sativus L.) adventitious root emergence under waterlogging stress. - Front Plant Sci. 7: $1515,2016$.

Yamauchi, T., Watanabe, K., Fukazawa, A., Mori, H., Abe, F., Kawaguchi, K., Oyanagi, A., Nakazono, M. Ethylene and reactive oxygen species are involved in root aerenchyma formation and adaptation of wheat seedlings to oxygendeficient conditions. - J. exp. Bot. 65: 261-273, 2014.

Yang, S.F., Hoffman, N.E.: Ethylene biosynthesis and its regulation in higher plants. - Annu. Rev. Plant Physiol. 35: 155-189, 1984.

Yao, Y.-X., Li, M., Zhai, H., You, C.-X., and Hao, Y.-J.: Isolation and characterization of an apple cytosolic malate dehydrogenase gene reveal its function in malate synthesis. J. Plant Physiol. 168: 474-480, 2011.

Yu, F., Han, X., Geng, C., Zhao, Y., Zhang, Z., Qiu, F.: Comparative proteomic analysis revealing the complex network associated with waterlogging stress in maize (Zea mays L.) seedling root cells -. Proteomics 15: 135-147, 2015.

Zhai, L., Liu, Z., Zou, X., Jiang, Y., Qiu, F., Zheng, Y., Zhang, Z.: Genome-wide identification and analysis of microRNA responding to long-term waterlogging in crown roots of maize seedlings. - Physiol. Plant 147: 181-193, 2013.

Zhu, X., Li, X., Jiu, S., Zhang, K., Wang, C., Fang, J.: Analysis of the regulation networks in grapevine reveals response to waterlogging stress and candidate gene-marker selection for damage severity. - Royal Soc. Open Sci. 5: 172253, 2018.

Zou, X., Jiang, Y., Liu, L., Zhang, Z., Zheng, Y.: Identification of transcriptome induced in roots of maize seedlings at the late stage of waterlogging. - BMC Plant Biol. 10: 189, 2010.

Zou, X., Tan, X., Hu, C., Zeng, L., Lu, G., Fu, G., Cheng, Y., Zhang, X.: The transcriptome of Brassica napus L. roots under waterlogging at the seedling stage. - Int. J. mol. Sci. 14: 2637-2651, 2013. 